\title{
Phytochemical competence and pharmacological perspectives of an endangered boon-Costus speciosus (Koen.) Sm.: a comprehensive review
}

\author{
Saima Sohrab, Pratibha Mishra and Sanjay Kumar Mishra* (D)
}

\begin{abstract}
Background: Costus speciosus (Koen) Sm. popularly known as crepe ginger or spiral ginger and insulin plant is a perennial rhizomatous herb contain variable number of medicinally important bioactive phytochemicals having intensive pharmacological effects due to antioxidant, antimicrobial, insecticidal, anticancerous, and antidiabetic properties. This plant is widely distributed throughout India and has tremendous ethnobotanical uses. This review article is the coalescence of the distribution, morphology, phytochemistry, pharmacology, effect, and mode of action of pharmacologically active principles of Costus speciosus.

Main body: The therapeutic potential possessed by the plant is mainly the attribution of the bioactive compounds such as phenolics, steroids, alkaloids, flavonoids, saponins, terpenoids, and tannins, which are found to be present in different parts of the plant. Bioactive constituents like diosgenin, gracillin, dioscin, prosapogenins A and B of dioscin, eremanthin, costunolide, $\beta$-sitosterol, $\beta$-D-glucoside, $\beta$-carotene, a-tocopherol quinine, dihydrophytylplastoquinone, 5a-stigmast-9(11) en3 $\beta$-ol, tetracosanyl octadecanoate, methyl hexadecanoate, methyl octadecanoate, cycloartenol, cycloartanol, and cycloalaudenol are specifically found in C. speciosus. This review also focuses on the possible mechanisms followed by these bioactive compounds while exhibiting various pharmacological properties. Because of the presence of diosgenin, this plant is given the name "insulin plant." Diosgenin along with an important sesquiterpene, costunolide, performs significantly high antioxidant, anticancer, and antidiabetic activities. Besides these properties, insecticidal, antifungal, antibacterial, and anthelminthic properties have also been discussed. This plant needs to be given more emphasis as it is exploited at the commercial level by the pharmaceutical industries, conservation status is getting poorer, and it is already in a near-threatened state. Therefore, more systematic and intensive research should be done in a sustainable manner.

Conclusion: Spiral ginger plant shows diverse pharmacological effects due to presence of variety of bioactive phytochemicals, but the compounds like diosgenins, costunolides, eremanthin, and arbusculin are highly specific that exhibit effective antidiabetic, anticancerous, and antioxidative properties through different mechanism. Thus, C. speciosus can be exploited as an economically sustainable source of effective drugs against deadly diseases like diabetes and cancers with less or no side effects, and further research is needed to explore the intricacy of its pharmacological actions with human trials.
\end{abstract}

Keywords: Zingiberaceae, Costus, Costunolide, Diosgenin, Antidiabetic potential

*Correspondence: sanjaiy1975@gmail.com

Department of Botany, Ewing Christian College (University of Allahabad),

Uttar Pradesh, Prayagraj 211003, India 


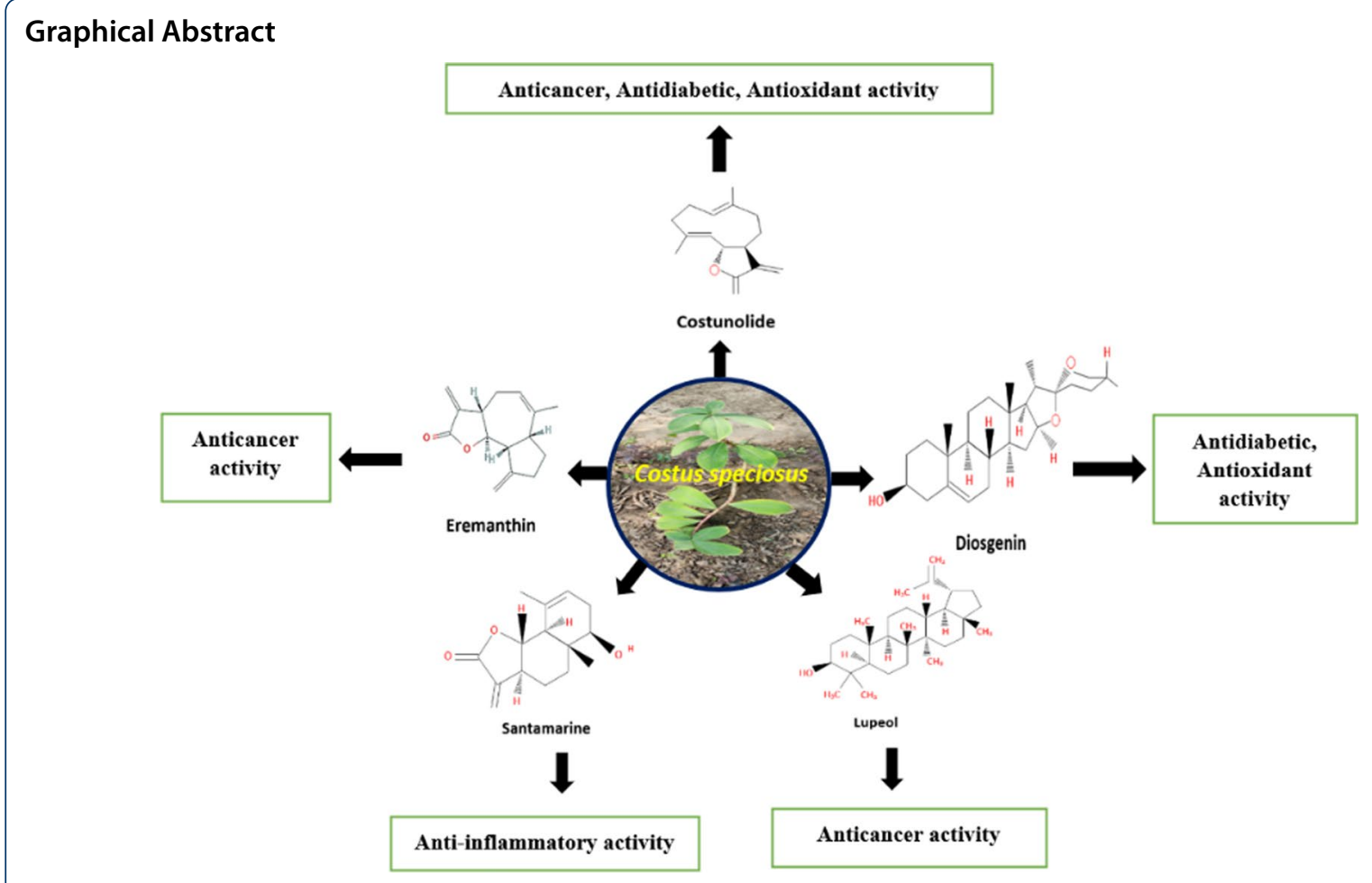

\section{Background}

There have been phenomenal developments in the field of synthetic drugs, their huge production, and easy availability, but despite these facts, these drugs have failed to provide adequate and proper medical relief to the common man. It is mainly because of their exorbitant prices and complicated side effects. Therefore, there is dire need to investigate for more potent, reversible, and less toxic drugs that could be achieved from the natural compounds of plants (Lewis 2001).

The attributions of plants to humankind are far beyond just providing the source for food and shelter but is also to serve as the storehouse of remedies against different diseases, which can be substantiated by the report of WHO that about $80 \%$ of the world's population, to meet their medicinal needs, is dependent on medicinal plants or herbs, as shown in Fig. 1. Medicinal plants contain rich bioactive compounds which contribute significantly in the pharmacopoeial as well as modern synthetic drugs, and their demand is expanding throughout the world which compels the need for firm regulation on the use of vegetal herbs. Good agricultural and collection practices have been initiated by WHO which provide guidelines for the quality assurance, safety and effectiveness of the medicinal plants and the herbal products derived from them, which would help in maintaining the sustainable consumption of herbal drugs (WHO Guidelines on
Good Agricultural and Collection Practices (GACP) for Medicinal Plants 2012). The use of herbal remedies is expanding in India also; for example, the reports of All India Trade Survey of Prioritized Medicinal Plants 2019 have highlighted the increase of $50 \%$ in the demand of medicinal plants; however, decline of $26 \%$ in the availability of these plants was also reported. Moreover, despite being one of the 17 mega-biodiversity countries and with the abundance of more than 8000 medicinal plant species (Botanical Survey of India 2019), the assessment of Indian and total world herbal market in 2019 revealed that the contributive share of India in the world export has been quite low (India hold US\$ 56.6 million share, while world herbal trade was US\$ 120 billion) which may be due to less advanced agricultural practices and lack of

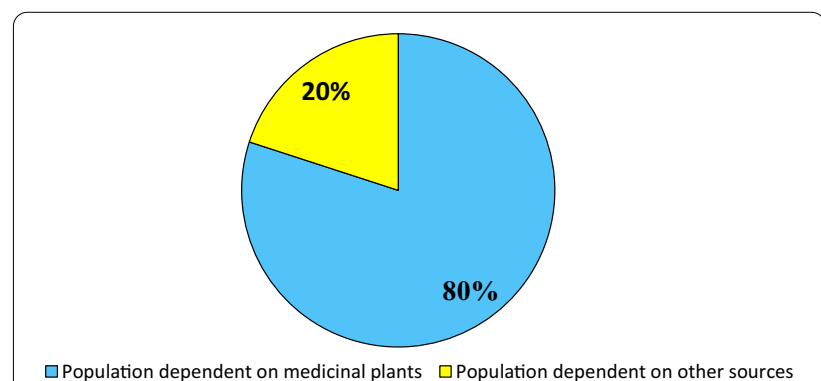

Fig. 1 Chart showing dependency of world's population on medicinal plants (WHO 2002; Ozioma and Okaka 2019) 
firm regulatory framework for quality control, processing and marketing of medicinal plants (India Brand Equity Foundation 2020). National Medicinal Plants Board has been established by the Government of India which works in effective coordination with other concerned bodies to regulate the cultivation, consumption, and conservation of medicinal plants (National Medicinal Plants Board 2021).

Furthermore, there is growing interest in the use of natural antioxidants for expanding the shelf-life of food materials in place of synthetic antioxidants like butylated hydroxyanisole (B.H.A), butylated hydroxytoluene (B.H.T.), and tertiary butyl hydroquinone (T.B.H.Q). Studies have shown that these food additives, used by the food processing industries to prevent lipid peroxidation and also have applications in cosmetics, have been reported to possess possible toxic and carcinogenic effects on health (IARC, 1986). In view of this, urge for extracting natural antioxidants and other pharmacologically significant compounds from plant sources have been showing interest among researchers in recent years; therefore, these phytoconstituents with reduced cytotoxicity and side effects could be employed in pharmaceutical industries as well as in food sectors (as food additives for having better shelf life). There is also an increase in the number of microorganisms that are resistant toward traditional antibiotics being currently used and has become a grave concern worldwide (Gyawali and Ibrahim 2014). Therefore, the study of antimicrobial and antioxidant compounds derived from plants that have the potential to replace traditional synthetic antimicrobial agents must be done imperatively (Gyawali and Ibrahim 2014; Sharifi-Rad et al., 2017).

An important source of new chemical substances with potential therapeutic effects is the natural aromatic and medicinal plants (Kaushik and Jalalpure 2011), as these plants are reported to contain a broad range of bioactive compounds that are usually produced as secondary metabolites such as phenolic acids, flavonoids, coumarins, tannins, stilbenes, and lignans; nitrogen compounds like amines, alkaloids and betalains, vitamins, carotenoids, and other metabolites of endogenous nature which possess extensive biological activities such as antioxidant, anti-inflammatory, antiaging, antibacterial, antitumor, and other pharmacological potentiality (Karimi et al. 2013). Much of these bioactive compounds have been reported to be present extensively in the members of family Zingiberaceae (Habsah et al. 2000; Mau et al. 2003). The ginger family contains plants of vital importance that include shell gingers (Alpinia), ginger (Zingiber officinale), summer tulip (Curcuma alismatifolia), black zedoary or black turmeric (C. caesia), turmeric (C. longa), ginger lily (Hedychium), torch ginger (Etlingera elatior), and cardamom (Amomum elettaria) (Jiang et al. 2000).

Among these, the exclusive medicinal plant, Costus Speciosus, popularly known as spiral ginger, has been recognized for its ethnomedicinal uses due to its high pharmacognostic potentials. In the present review article, efforts have been made to delve deep into a wide range of pharmacological potential of the medicinal plant, $C$. speciosus, serving as a healthier and safer multipotential source for the replacement of harmful synthetic drugs, artificial preservatives, and food additives and also pave the way to find some valuable chemical compounds that might prove helpful in the eradication of various diseases. Also, bring to the notice of conservationists, ecologists, researchers, and stakeholders to strategize its conservation, monitor its ecosystem, and develop programs for the restoration of this medicinally important species (Maji et al. 2020).

\section{Main text}

\section{Distribution of Costus speciosus (Koen.) Sm.}

The distribution of $C$. speciosus has been reported in different continents including Africa, Asia, North America, and Oceania, but it is basically the native of Southeast Asia and Malaysia. It is native to Asian countries like Bangladesh, Bhutan, Indonesia, China, India, Hong Kong, Malaysia, Nepal, Philippines, Singapore, Sri Lanka, Taiwan, Thailand, Vietnam, and Myanmar. However, in North America and Oceania this species occurs as introduced species. In North American countries like Cuba, the USA, Hawaii, and in many parts of Oceania, this plant is invasive in origin.

In India, the plant has a wide range of spread from Northern regions (through Himalayan hills) and Himachal Pradesh to Assam, West Bengal, and Central India (Vindhya Satpura hills); Southern regions include Andhra Pradesh (Eastern Ghats), Maharashtra (Western Ghats), Karnataka, Tamil Nadu, and Kerala (Pawar and Pawar 2014) with the exclusion of some states like Gujarat, Haryana, Punjab, and peninsular India as these states have arid and semi-arid geographical conditions (Anonymous 2007), which is not suitable for the growth of this plant. C. speciosus is called by different vernacular names (Table 1) in different parts of the country (Srivastava et al. 2011; Swati and Agarwal 2015; Mazumdar and Hussain 2021).

\section{Description of the plant}

\section{Taxonomy of Costus speciosus}

Spiral ginger or Crepe ginger belongs to the family Zingiberaceae of order Zingiberales. This plant shows similarities with other Zingiberaceae members in their floral characters and inflorescences (Specht and 
Stevenson 2006). However, it can be distinguished from other members of the family Zingiberaceae because of the presence of remarkable spiral stems and spiral phyllotaxy (Kirchoff and Rutishauser 1990). Because of this reason, the genus Costus was placed in a separate family, Costaceae, which is known to include approximately 175 species (Ariharan et al. 2012). The taxonomic position of C. speciosus is given in Table 2.

\section{Morphology}

Costus speciosus (Koen) Sm. (Zingiberaceae) is an ornamental erect, rhizomatous, perennial succulent herb, up to $2.7 \mathrm{~m}$ high, with tuberous rootstock (Gupta 2010). The rhizome of the plant has nodes, and internodes and the lower parts of the rhizome are sheathed, while going upward, it is leafy. The stem arising from the horizontal rhizome is sub-woody at the base. Leaves are broad sessile, thick, elliptic to oblong or oblanceolate-oblong, acute or acuminate, often cuspidate and arranged spirally on the stem. The dorsal side of the leaves is glabrous, while the ventral surface is silky and pubescent (Maji et al. 2020).

The inflorescence of the plant is terminal, ellipsoid or ovoid, bracteate, and bracteolate with bright red bracts and pale red bracteoles. The shape of the bract is found to be ovate with a sharply pointed apex having leathery and pubescent texture. The flowers are large and white and present in thick cone-like terminal spikes. The calyx is reddish black, tri-lobed, rigid, deltoidovate, and cuspidate with sericeous apex. Tube-like corolla (approximately $1 \mathrm{~cm}$ ) has oblong-elliptic lobes

Table 1 Vernacular names of Costus speciosus (Srivastava et al. 2011; Swati and Agarwal 2015; Mazumdar and Hussain 2021)

\begin{tabular}{ll}
\hline Name of the states & Vernacular names \\
\hline Assam & Tara \\
Bengali & Keu, Keumut \\
Guajarati & Paskarmula, Valakdi \\
Kannada & Changalvakostu, Chikke \\
Manipuri & OkchakKhombi \\
Malayalam & Channakoova \\
Marathi & Penva, Pinnha, Kobee, Peva \\
Mizo & Sumbul \\
Oriya & Kushtha \\
Sanskrit & Kembuka, Kebuka, Kembu \\
Tamil & Kostam \\
Telugu & Kashmeeramu, Cengalvakostu \\
Hindi & Keu, Keukand, Kemuka, Kemua \\
English & Cane red, Crepe ginger, spiral \\
Latin name & flag, spiral ginger \\
\hline
\end{tabular}

Table 2 Taxonomic status of Costus speciosus (Banerji et al. 1982)

\begin{tabular}{ll}
\hline Taxonomic classification & \\
\hline Kingdom & Plantae \\
Subkingdom & Tracheobionta \\
Super division & Spermatophyta \\
Division & Magnoliophyta \\
Class & Liliopsida \\
Subclass & Zingiberidae \\
Order & Zingiberales \\
Family & Zingiberaceae/Costaceae \\
Genus & Costus \\
Species & speciosus \\
\hline
\end{tabular}

(approximately $5 \mathrm{~cm}$ ) with white or red apex. White, trumpet-shaped labellum $(6.5-9 \mathrm{~cm})$ is present whose apex is crisped and toothed, with overlapping edges. Stamen (approximately $4.5 \times 1.3 \mathrm{~cm}$ ) is petaloid, white in color with an orange-yellow base, urn-shaped, and covered with short soft hairs (pubescent). The fruit is capsular (approximately 1.5-2 cm), red in color, globose trigonous, and a bit woody. They produce black and glossy seeds (5 in number) with white and fleshy aril (Srivastava et al., 2011; Mazumdar and Hussain 2021). In India, during mid of April-May, rhizomes start to sprout their buds and the growth of the plant is at peace when there is the rainy season, usually in July, and grows vegetatively till the month of September and October and then flowering continues till the end of October. After this stage is finished, fruits get ripened and all the leaves have fallen and the plant finally dies. But the underlying rhizome remains in the dormant stage from December to March, and again new sprouts come during the month of April of the subsequent years (Maji et al. 2020). Detailed description of the plant is depicted in Table 3 and Figs. 2 and 3.

\section{Propagation, cultivation, and conservation}

The propagation of the plant is done vegetatively by rhizomes and also by seeds as they are dispersed by rodents and birds when they feed on fruits (Englberger 2009). Division of culms and stem cuttings have also been used for propagation purposes (Pawar and Pawar 2014). It has been studied that when provided with the ideal growing conditions, shoots will grow and become a clump as wide as $3 \mathrm{ft}$ in the second year. According to the studies done by Merina Benny (2004), the seed germination percentage is above fifty percent under natural conditions (Benny 2004). But still, there is a need to develop a standard practice of cultivation of this plant as any such standardization of cultivation methods has not yet been done. 
Table 3 Characteristic features of Costus speciosus (Devi and Urooj 2010; Singh et al., 2014)

\begin{tabular}{|c|c|c|}
\hline \multicolumn{3}{|c|}{ Features of $C$. speciosus } \\
\hline Plant type & \multicolumn{2}{|c|}{ Herbaceous, perennial, seed propagated, and vegetatively propagated } \\
\hline \multirow[t]{2}{*}{ Height of the plant } & In frost-free areas & Up to $3.1 \mathrm{~m}$ \\
\hline & In cooler regions & About $1.8 \mathrm{~m}$ \\
\hline \multirow[t]{2}{*}{ Stem } & Stem sub woody at the & \\
\hline & No characteristic taste & \\
\hline \multirow[t]{12}{*}{ Leaves } & Number of leaves & Usually $15-20$ \\
\hline & Color of leaves & Dark green \\
\hline & Arrangement & Alternate and Spiral arrangement \\
\hline & Length & $5.7-7.5 \mathrm{~cm}$ \\
\hline & Shape & Sessile or sub-sessile \\
\hline & Leaf blade & Oblong or lanceolate \\
\hline & Dorsal surface texture & Silky instances \\
\hline & Ventral surface texture & Silky and pubescent \\
\hline & Petiole & $5-7 \mathrm{~mm}$ \\
\hline & Leaf sheath & Coriaceous (leathery texture) \\
\hline & Ligule & Absent \\
\hline & Taste and odor & No characteristic taste and odor \\
\hline \multirow[t]{7}{*}{ Inflorescence } & Type of inflorescence & Spike (dense spike) $5-12.5$ by $3.8-7.5 \mathrm{~cm}$ \\
\hline & Flower color & Large, white, and clustered in terminal globose heads \\
\hline & Bracts & $\begin{array}{l}2-3.2 \mathrm{~cm} \text { long, ovate, acuminate, often pungently mucronate, large, bright red, or shiny } \\
\text { brown in color }\end{array}$ \\
\hline & Bracteole & Pale red, Solitary below the calyx, and $1.6 \mathrm{~mm}$ long \\
\hline & Calyx & Red, $3.2 \mathrm{~cm}$ long, lobes $6 \mathrm{~mm}$ long, and deltoid-ovate cuspidate \\
\hline & Corolla & $\begin{array}{l}\text { Corolla tube as long as the calyx; lobes ovate-oblong, apiculate, the lateral lobes } 3.5 \text { by } \\
1.3 \mathrm{~cm} \text {, and the dorsal } 4 \text { by } 2 \mathrm{~cm}\end{array}$ \\
\hline & Taste and odor & Characteristic taste and odor \\
\hline \multicolumn{2}{|l|}{ Labellum } & White, trumpet-shaped, toothed, and crisped apex, overlapping edges \\
\hline \multicolumn{2}{|l|}{ Stamen } & $\begin{array}{l}\text { Crest yellow stamens, petaloid, and globose single stamen, the style running between the } \\
\text { two halves of the large anther }\end{array}$ \\
\hline \multicolumn{2}{|l|}{ Fruit } & Globosely trigonous red-colored capsule \\
\hline \multicolumn{2}{|l|}{ Seeds } & Black and glossy approximately 3 mm black, five in number with a white fleshy aril \\
\hline
\end{tabular}

A report by the World Health Organization has estimated that by the end of 2010, there were around 3.2 crores of diabetic patients in India and it was mentioned that India has the fastest-growing population of this disease. C. speciosus has become the great demand of the day as it provides an excellent alternative source of diosgenin and other synthetic and viable drugs against diabetes. But this imposes the threat of extinction as there is indiscriminate collection of this plant for its rhizome from the wild due to which it has been noticed that the Costus plant is disappearing very rapidly from its natural habitat. This has urged the researchers to study about the suitable tissue culture and micropropagation methods for conservation and large-scale production of C. speciosus as the rate of regeneration of this threatened species is quite slow. It is imperative to go in for augmentative research such that it can be provided to pharmaceutical industries, nurseries, and farmers at affordable prices (Rani et al. 2012). For this, various biotechnological approaches are being developed so that successful propagation or rather a micropropagation can be done from pseudostem without causing significant damage to the main mother plant (Philip Robinson et al. 2009). Shoot tip proliferation, multiplication at the clonal level, and in vitro production of rhizome have been done in this direction, and an extremely high percentage of regeneration of shoot was reported when triacontanol was used, which is illustrated in Fig. 4.

\section{Ethnomedicinal uses}

Medicinal plants have played a great role as an alternative and complementary medicinal source of most of the synthetic drugs in modern use. For this reason, many countries like India, Sri Lanka, West Indies, China, America, 

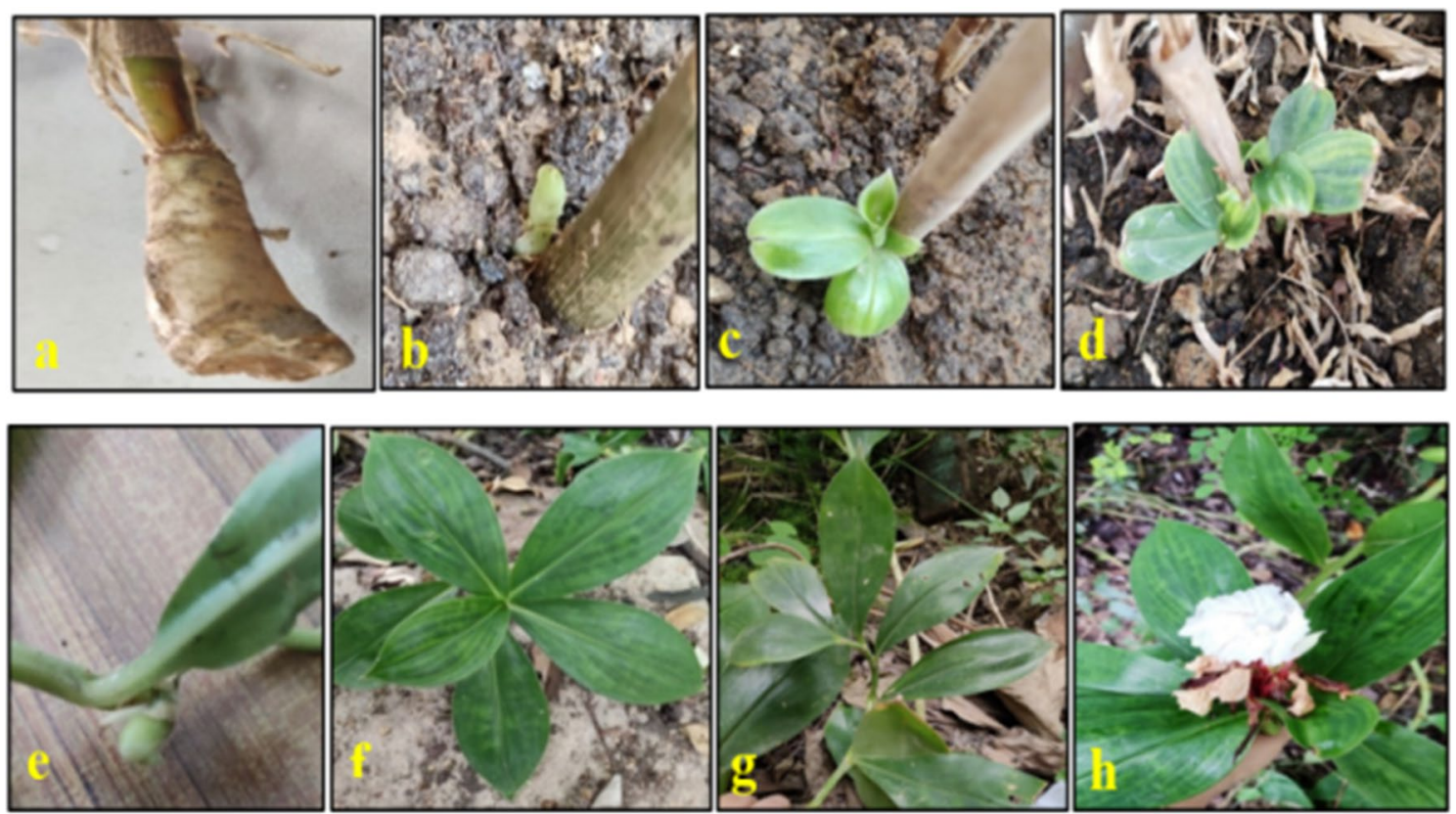

Fig. 2 a Young rhizome; $\mathbf{b}$ new shoot growth; $\mathbf{c}$ and $\mathbf{d}$ young leaves; e horizontal roots; $\mathbf{f}$ and $\mathbf{g}$ mature plant; $\mathbf{h}$ flower

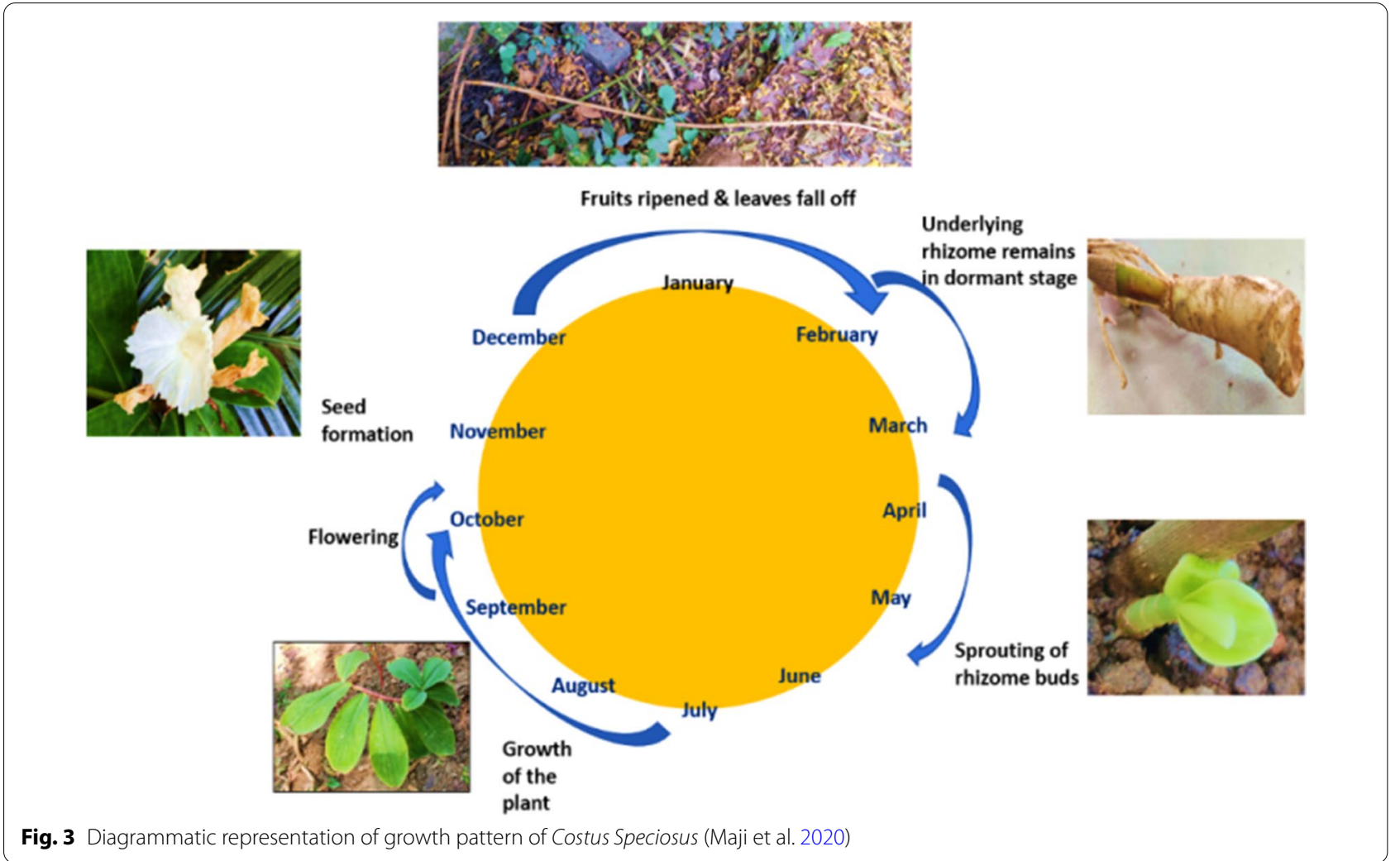


and Africa have recognized C. speciosus for its ethnicmedico-botanical uses (Maji et al. 2020). India witnesses the use of this plant as one of the traditional medicines, and its medicinal values' ascription has been defined in Ayurveda also (Thambi and Shafi 2015). This plant has been used as food as well as medicine by the tribal people of hills of Southern regions of India (Pawar and Pawar 2014). Except for the regions of the northeastern and southern parts of India, C. speciosus is still recognized as an underexplored species.

Studies show that the leaves, stem, and most notably the rhizome of $C$. speciosus are attributed with various medicinal properties. For instance, the roots and rhizomes of the plant have been reported to be used against disorders like rheumatism, anemia, bronchitis, skin diseases, constipation, jaundice, flatulence, asthma, helminthiasis, leprosy, pneumonia, dropsy, inflammation, hiccough, fever, and some urinary diseases in which urination is accompanied by the sensation of burning (Nair et al. 2014; Maji et al. 2020). Various other properties of the rhizomes show that they are strongly laxative in effect (purgative), astringent, depurative, anthelmintic, tonic, acrid, febrifuge, expectorant and are also believed to improve digestion (Nadkarni 2009; Gupta, 2010). The juice made up of the rhizomes of $C$. speciosus is used to cure leprosy and also for abortion (Anonymous 2007), and it is known to provide a cooling effect and thus used in headaches (Gupta 2010). Besides, the traditional use of the rhizomes, leaves, and stem too has been used for their medicinal properties; for example, the infusion of leaves and stem decoction has a sudorific effect and thus is utilized to treat high fever patients; sometimes, they are used in the bruised form and applied to the affected person suffering from the fever (Anonymous 2007; Malabadi 2005). In addition, the sap of young leaves and stems is used in eye and ear infections (Srivastava et al. 2011), catarrhal fever, cold and cough, and also against snake bites (Anonymous 2007; Nadkarni 2009).

Despite its significance as an ethnomedicinal drug for ages and the presence of diverse types of

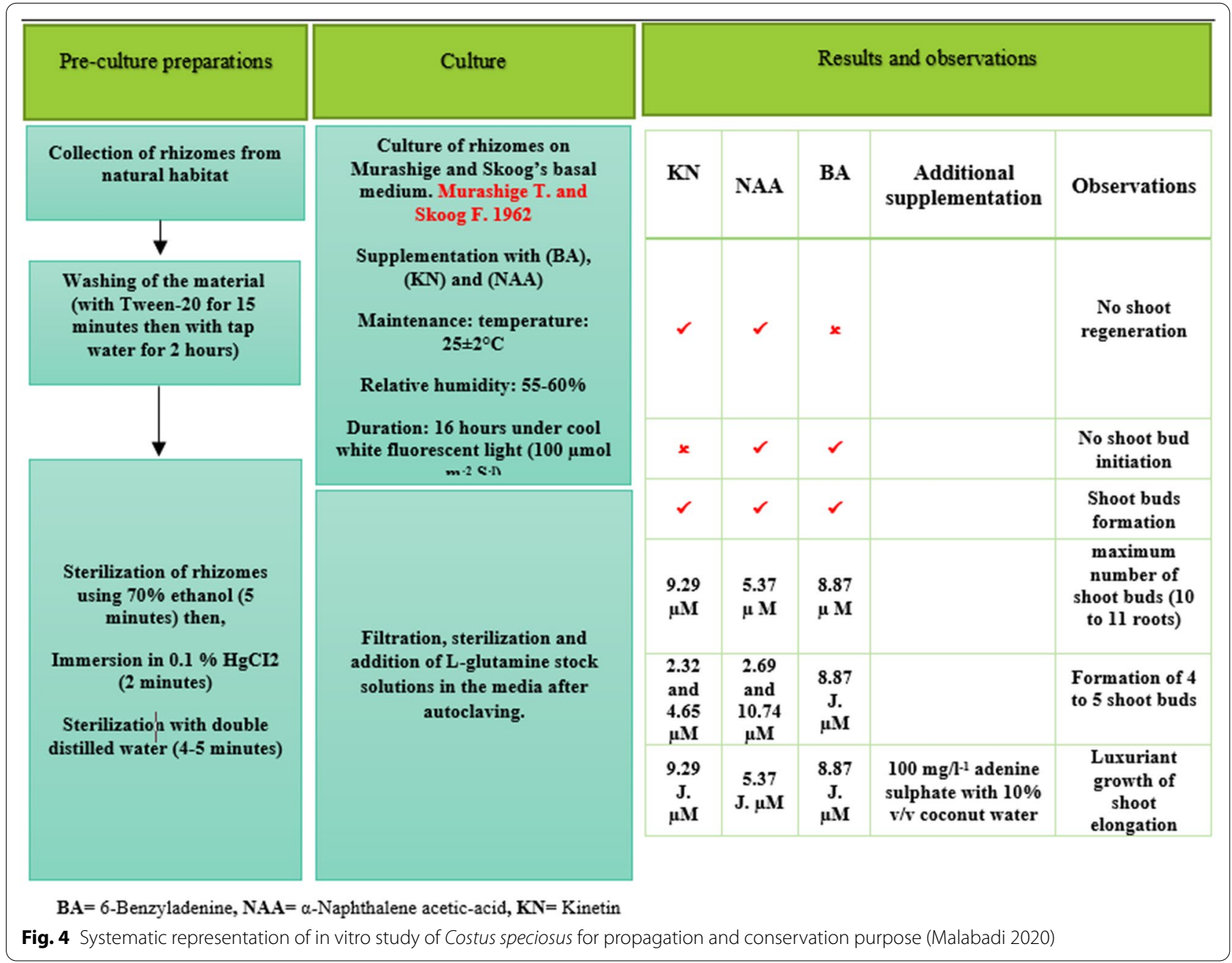


pharmacologically active phytochemical constituents, very limited authentic and verified information is available on marketed formulation and a patent on C. speciosus due to the lack of an appropriate number of human trials. However, certain Indian ayurvedic and natural health-product companies are now coming forward in this regard; for instance, Dabur India Limited, one of the leading ayurvedic companies, has developed an ayurvedic formulation based on Costus speciosus which is traded as Ketaki (crepe ginger/kemuka) powder, used for the treatment of hyperlipidemia, obesity, and management of diabetes and menstrual irregularities. In addition, $C$. speciosus extract, along with other herbs, has been used in the patented process for anti-inflammatory and analgesic preparation by Khamar (2002) with patent number WO-02/085394 by World Intellectual Property Organization under Patent Cooperation Treaty. However, for the betterment of the public health and promotion of natural and safer remedies for ailments more such formulations and developments should be encouraged (Fig. 5).

\section{Phytochemistry of $C$. speciosus Phytochemical composition}

Costus speciosus is reported to contain an abundance of phytochemicals of diverse nature such as phenolics, steroids, alkaloids, flavonoids, saponins, terpenoids, and tannins, which are found to be present in different parts of the plant. For instance, studies have shown that the leaves of the plant of C. speciosus contain $\alpha$-amyrinsterate, lupeol, palmitates, and $\beta$-amyrin (Srivastava et al. 2011; Rani et al. 2012). Other phytochemicals like triterpenes, aliphatic hydroxy ketones, fatty acid, oxa-acid, abscisic acid, starch mucilage, corticosteroids, and tigogenin were reported from the rhizome of the plant (Pawar and Pawar 2014). Some other bioactive constituents that are specifically found in C. speciosus are diosgenin, gracillin, dioscin, prosapogenins $\mathrm{A}$ and $B$ of dioscin, eremanthin, costusosides, $\beta$-sitosterol, $\beta$-D-glucoside, $\beta$-carotene, $\alpha$-tocopherol quinine, dihydrophytylplastoquinone, $\quad 5 \alpha$-stigmast-9(11)en $3 \beta$-ol,

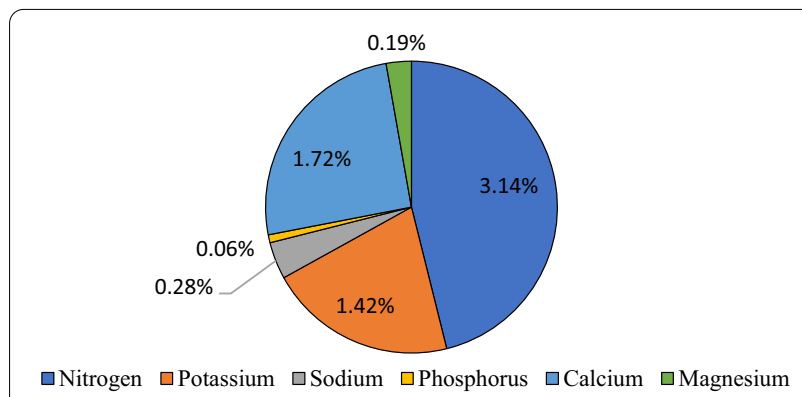

Fig. 5 Trace elements found in Costus speciosus (Singh 2011) tetracosanyl octadecanoate, methyl hexadecanoate, methyl octadecanoate, cycloartenol, cycloartanol, and cycloalaudenol (Eliza et al. 2009; Nehete et al. 2010; Singh et al. 2014; Pawar and Pawar 2014). Apart from the leaves and rhizomes, seeds have also been shown to conserve $\alpha$-tocopherol, dihydrophytylplastoquinone, and its 6-methyl derivatives (Rani et al. 2012). Seeds of the plant produce oil which shows the prevalence of some saturated fatty acids, for example, myristic acid, stearic acid, behenic acid, palmitic acid, and monounsaturated fatty acid like oleic acid (monounsaturated omega-9 fatty acid), gadoleic acid, and polyunsaturated fatty acid include linoleic acid (polyunsaturated omega-6 fatty acid) (Rani et al. 2012; Rastogi and Mehrotra 2004a, b) (Fig. 6). To determine the chemical components of the complete seed after testing it for its oil content, seeds of the $C$. speciosus have been defatted, which revealed the existence of bioactive phytoconstituents such as glucose, rhamnose, galactose, and diosgenin (Malabadi et al., 2016). Recent researches done by Kumar et al. (2018a, b) using techniques such as GC/MS, ESI-MS/UPLC/MS, and NMR confirmed the presence of a diverse range of metabolites like terpenoids, phenolic compounds, sterols, fatty acids, and amino acids from the rhizomes and leaves of C. speciosus. Dehydrocostus lactone, arbusculin A, santamarine (douglanin), and reynosin are some of the sesquiterpenes isolated and identified from the rhizomes of the plant (Al-Attas et al. 2015). Srivastava et al. (2011) have reported the presence of diosgenin in different parts of the plant, which is shown in Fig. 7. Another most important sesquiterpene, Costunolide, which has tremendous pharmacological properties, has also been reported from C. speciosus (Duraipandiyan et al. 2012).

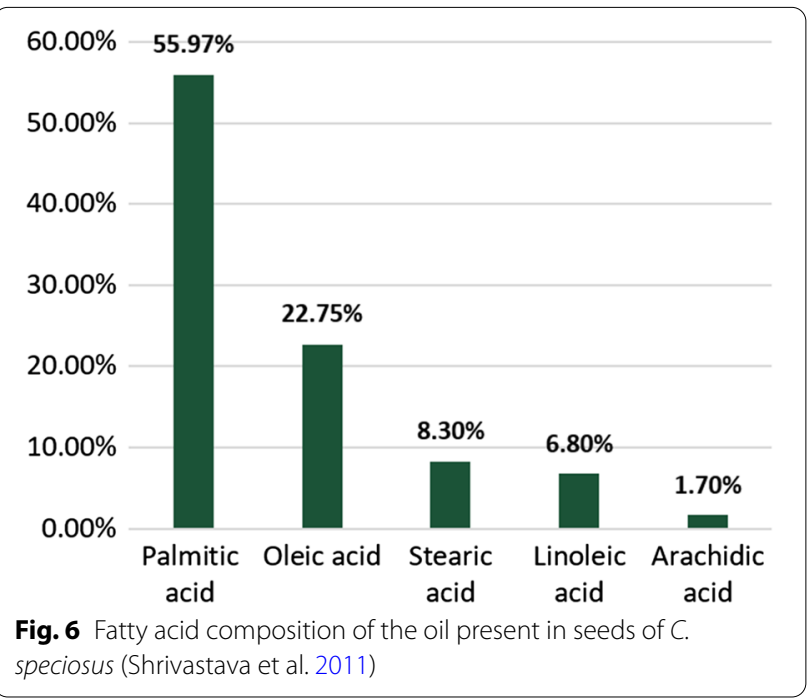


Structures of some of the bioactive chemical ingredients found in Costus speciosus are shown in Fig. 8. From the analytical studies done by Abirami et al. (2014), the concentration of different phytoconstituents varies in different parts of the plant; for instance, the compounds of phenolic nature were reported to be most abundant in the leaves $(119.02 \mathrm{mg} / 100 \mathrm{~g})$; however, in rhizome $69.49 \mathrm{mg} / 100 \mathrm{~g}$ phenolic components were found which was still more than the concentration present in the stem and roots $(65.24 \mathrm{mg} / 100 \mathrm{~g}$ and $30.88 \mathrm{mg} / 100 \mathrm{~g}$, respectively). Similarly, the flavonoid-rich part of the plant was a leaf with a concentration of $96.18 \mathrm{mg} / 100 \mathrm{~g}$, while 50.18 and $56.49 \mathrm{mg} / 100 \mathrm{~g}$ were reported from roots and stem, respectively. Another quantitative analysis to determine the percentage of concentration of crude bioactive compounds or chemical constituents in C. speciosus was done using $U V$-Visible spectrophotometry which evidently revealed the gratification of the plant with phenolic compounds $(25.4 \pm 0.4 \mathrm{mg} / \mathrm{g}$ of dry material) followed by tannin $(20.3 \pm 0.62 \mathrm{mg} / \mathrm{g}$ of dry material), saponin $(18.3 \pm 0.66 \mathrm{mg} / \mathrm{g}$ of dry material), flavonoid $(13 \pm 0.79 \mathrm{mg} / \mathrm{g}$ of dry material), terpenoid $(11.2 \pm 0.5 \mathrm{mg} / \mathrm{g}$ of dry material), alkaloid $(6.4 \pm 0.45 \mathrm{mg} / \mathrm{g}$ of dry material), steroid $(1.03 \pm 0.15 \mathrm{mg} / \mathrm{g}$ of dry material) (Raveendran 2015). In addition, the appreciable quantity of antioxidant phytoconstituents like ascorbic acid $(216 \pm 2.51 \mathrm{mg})$, $\alpha$-tocopherols $(25 \pm 0.81 \mathrm{mg}), \beta$-carotene $(184 \pm 6.8 \mu \mathrm{g})$, and glutathione $(407 \pm 2.58)$ (all the mentioned values were expressed based on per $100 \mathrm{~g}$ of dry material of the plant) has been reported by Devi and Urooj (2010). Besides these bioactive chemical compounds, C. speciosus is reported to contain certain trace elements, which are also required for the growth of the plant in a proper

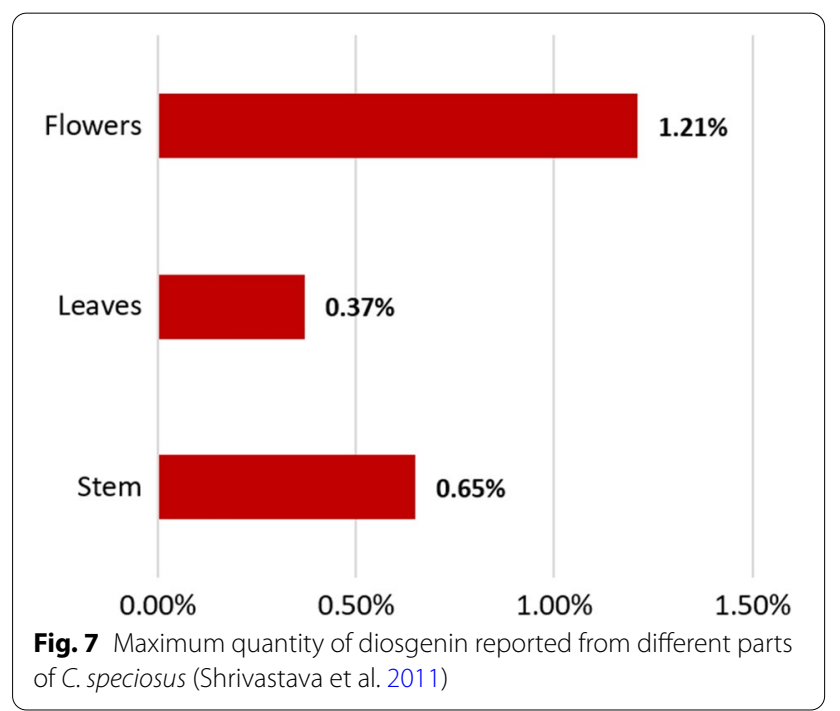

manner; however, they are needed in very small quantities. The rhizomes of the plant show the presence of $\mathrm{N}$, $\mathrm{K}, \mathrm{Na}, \mathrm{P}, \mathrm{Ca}$, and $\mathrm{Mg}$ and the amount in which they are found are represented in Fig. 5. Different phytochemicals present in different parts of the plant are categorized in Table 4.

\section{Physicochemical properties}

Physicochemical properties of the phytoconstituents are one of the main aspects to be evaluated, while their interactions with other biomolecules are studied as the potential of the chemical compounds to possess various pharmacological and therapeutic effects is associated with and influenced by these properties. Considering the implications of physicochemical properties of different parts of C. speciosus and extractive values for the same, using different solvents has been done in previous studies. Evaluation of physicochemical parameters such as moisture content, water-soluble content, alcohol soluble content, acid insoluble ash, water-soluble ash, total ash, and sulfated ash has been done using different solvents like methanol, petroleum ether, ethyl acetate, chloroform, and water by several workers (Shrivastava et al. 2011; Singh et al. 2014; Kala et al. 2016; Borkataky et al. 2014; Maji et al. 2020) as shown in Fig. 9. It has to be noted that variations occur in the values of the ash content as the physicochemical properties get affected by the variations in the geographical locations of the plant. In addition to this, various other parameters like saponification values $(179.84 \mathrm{mg}$ $\mathrm{KOH} / \mathrm{g})$, refractive index (1.4672), acid value $(23.54 \mathrm{mg}$ $\mathrm{KOH} / \mathrm{g})$, and specific gravity $(0.9125)$ of the oil content have been studied by Shrivastava et al. (2011).

\section{Different pharmacological properties of Costus speciosus}

Antioxidant activity

Antioxidants are the molecules that can inhibit the process of oxidation of other molecules by breaking the chain reactions of free radicals and also inducing the antioxidant enzymes of cells (Daisy et al. 2008). The antioxidants feed free radicals with electrons of their own, and in this process, they themselves do not become the free radicals. Investigative studies on free radicals have revealed that as the number of free radicals increases in the human body, it induces early aging in human beings (Halliwell 1991). Several factors decide the toxicity of free radicals like the kind of free radical, concentration, localization of production, and elimination kinetics (Nordgren and Fransen 2014). Superoxide anion, hydroxyl radical, singlet oxygen, peroxyl radical, alkoxy radical, and various other reactive 


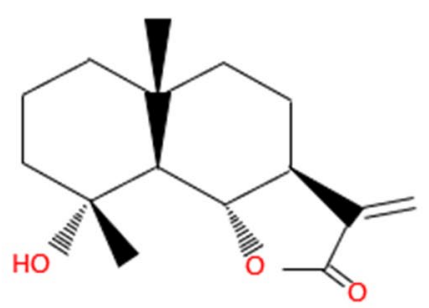

Arbusculin A

(Sesquiterpene lactone)

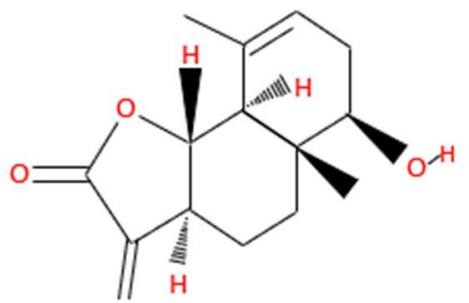

Santamarine

(Sesquiterpene

lactone)

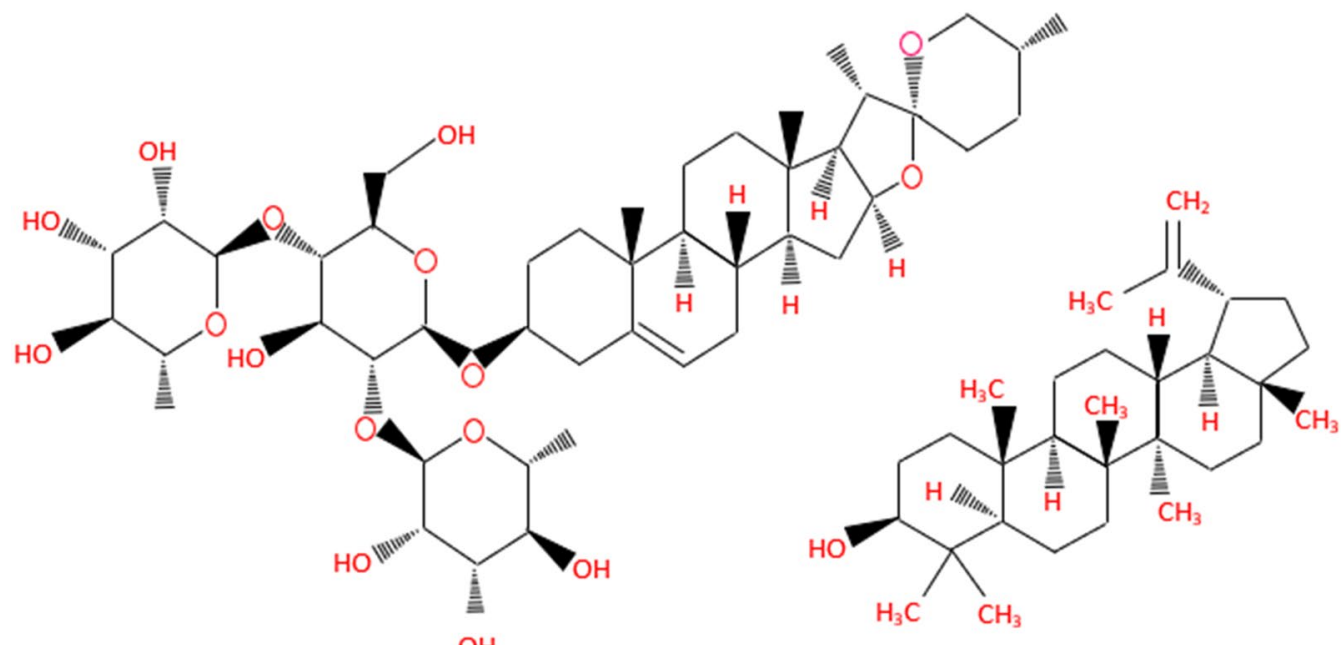

$\mathrm{OH}$

Dioscin (Saponin)

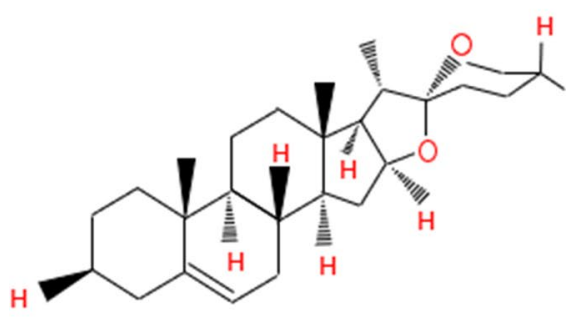

Diosgenin (Terpenoid)
Lupeol (Terpenoid)<smiles>C=C1O[C@H](/C=C/C)CC/C=C(/C)CC[C@@H]1C</smiles>

Costunolide (Terpenoid)

Fig. 8 Chemical structure of some important bioactive compounds of C. speciosus (Al Attas et al., 2015; Shrivastava et al., 2011; El-Far et al. 2018)

nitrogen species damage the cell organelles and cellular activities and bring the body of plants and animals under oxidative stress, which is the condition when the antioxidant defenses are outnumbered by the free radicals. The most common free radicals that all aerobic organisms produce are reactive oxygen species (ROS). Biological molecules like DNA, proteins, lipids, and lipoproteins are vulnerable targets for them as ROS can react very easily with them. If the DNA repair system fails to reverse the damages to DNA, this leads to harmful mutations and more likely develop into cancer (Beckman et al. 1994). Similarly, when the target molecules of these harmful oxidants are proteins, they inhibit the enzymes, denature, and degrade the proteins. Oxidative injury is caused by the peroxidation of lipids and causes pathophysiological disorders like diabetes, cirrhosis, atherosclerosis, arthritis, cancer, inflammation, diabetes, and genotoxicity (Halliwell 1991; Nehete et al. 2010; Sunitha, 2016). Another study shows that the length of the telomere of chromosomes 
Table 4 Phytochemicals found in Costus speciosus

\begin{tabular}{|c|c|c|c|}
\hline $\begin{array}{l}\text { Part of the } \\
\text { plant (Costus } \\
\text { speciosus) }\end{array}$ & Phytochemical constituents & Bioactive chemical compounds & References \\
\hline \multirow[t]{11}{*}{ Seeds } & Spirostanyl glycoside & Dioscin & \multirow{25}{*}{$\begin{array}{l}\text { Rastogi and Mehrotra (2004a, b), Chakre (2010), } \\
\text { Rani et al. (2012), Maji et al. (2020), Duraipandiyan } \\
\text { et al. (2012), Mazumder and Hussain (2021) }\end{array}$} \\
\hline & Steroid glycoside & $\beta$-Sitosterol- $\beta$-D-glucoside & \\
\hline & Steroidal saponins & Gracillin, Protodioscin & \\
\hline & Furostanolbisglycoside & Methyl protodioscin & \\
\hline & Phytosteroid sapogenin & Diosgenin & \\
\hline & Furostanol saponins & Costusosides & \\
\hline & Benzoquinones & $\begin{array}{l}\text { a-Tocopherolquinone, 6-methyldihydrophytyl- } \\
\text { plastoquinone, Dihydrophytylplastoquinone, }\end{array}$ & \\
\hline & $\beta$-sitosterol & 5a-Stigmast-9(11)-en-3ß-ol & \\
\hline & Saturated fatty acids & $\begin{array}{l}\text { Myristic acid, Stearic acid, Behenic acid, Palmitic } \\
\text { acid }\end{array}$ & \\
\hline & Monounsaturated fatty acid & Oleic acid, Gadoleic acid & \\
\hline & Polyunsaturated fatty acid & Linoleic acid & \\
\hline \multirow[t]{2}{*}{ Leaves } & Esters of palmitic acid & Lupeol Palmitates & \\
\hline & Triterpene & $\beta$-Amyrin, a-Amyrinsterate & \\
\hline \multirow[t]{12}{*}{ Rhizomes } & Monoterpenoids & Carvacrol & \\
\hline & Phytosterol & $\begin{array}{l}\text { Triacontanol, Sitosterol, Tetradecyl-5a- } \\
\text { stigmast-9(11)- en-3ß-ol }\end{array}$ & \\
\hline & Sesquiterpenes & Eremanthin, Costunolide & \\
\hline & Phytosteroid sapogenin & Diosgenin & \\
\hline & Allyl alcohol & Pinocarveol & \\
\hline & Sesquiterpene lactones & Reynosin, Santamarine, Arbusculin A & \\
\hline & Furostanolbisglycoside & Methyl protogracillin & \\
\hline & Monoterpene cyclic ether & Cineol & \\
\hline & Bicyclic sesquiterpenes & Cadinene & \\
\hline & Fatty acid ester & $\begin{array}{l}\text { 11-methylpentadecanoate, 13-Methylpenta- } \\
\text { decanoate }\end{array}$ & \\
\hline & Phytosteroid sapogenin & Diosgenin & \\
\hline & Saturated fatty acid & $\begin{array}{l}\text { Triacontanoic acid, } 14 \text { oxo-octacosanoic acid, } \\
14 \text { oxoheptacosanoic acid }\end{array}$ & \\
\hline
\end{tabular}

gets shortened due to oxidative stress (Gupta 2015). A brief description of different types of free radicals and damages caused by them is given in Table 5 .

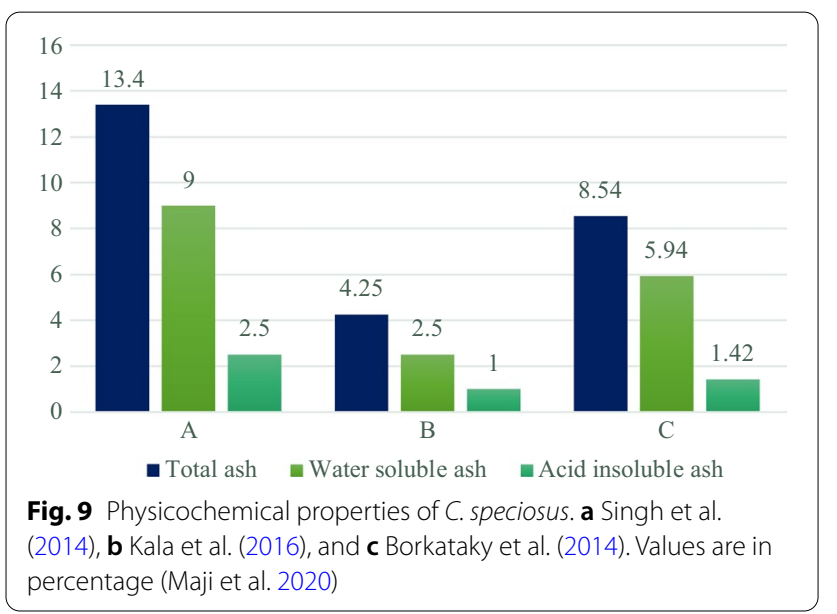

Antioxidants derived by the plants are the most efficient solution to the pathologies driven by free radical attacks (Girgis et al. 2015). For this, plants show effective counteraction mechanisms. One of the ways to deal with oxidative stress is scavenger enzymes that include glutathione S-transferases (EC 2.5.1.18), superoxide dismutase (EC 1.15.1.1), glutathione peroxidase (EC 1.11.1.9), and catalase (EC 1.11.1.6) (Gottfredsen et al. 2013). These enzymatic antioxidant defense systems prevent toxic hydroxyl ion formation ( $\mathrm{HO} \bullet$ ) mainly by metabolizing superoxides, lipid peroxides, and hydrogen peroxides (Pietta 2000). For instance, superoxide dismutases, one of the chief cellular antioxidants, constituting a group of metalloenzymes, helps in the protection of the cell from the damaging and excessive concentration of free radical of superoxide anion $\mathrm{O} 2-$ by decreasing them through the dismutation reaction in which the free radical $(\mathrm{O} 2-)$ is converted into hydrogen peroxide 
Table 5 Different types of free radicals and possible damages caused by them

\begin{tabular}{ll}
\hline Types of free radicals & Damages caused by the free radicals \\
\hline $\begin{array}{l}\text { Superoxide anion } \\
\text { Hydroxyl radical }\end{array}$ & $\begin{array}{l}\text { Can damage mitochondria and DNA } \\
\text { Capable of damaging organic molecules present close to it, which include } \\
\text { carbohydrates, lipids, proteins, and DNA }\end{array}$ \\
Singlet oxygen & Causes oxidation of low-density lipid \\
Peroxyl radical & Involved in food spoilage \\
Alkoxy radical & Can cause DNA mutations and apoptosis \\
Reactive nitrogen species (RNS) & $\begin{array}{l}\text { May cause risk for cancer development, hepatitis or other chronic inflammatory } \\
\text { processes }\end{array}$ \\
\hline
\end{tabular}

and molecular oxygen and shows therapeutic potential against cancer, aging, various inflammatory and neurodegenerative diseases (Younus 2018). Another scavenger enzyme, catalase, which, like superoxide dismutase, shows first-line defense against oxidative stress, causes decomposition of the hydrogen peroxide, and nullifies its harmful effects by forming molecules of innocuous nature, i.e., water and oxygen. Similarly, glutathione peroxidase, an intracellular enzyme, protects from oxidative damage by reducing hydrogen peroxide and lipid hydroperoxides to water and corresponding alcohols, respectively (Nandi et al. 2019).

The scavenger enzymes mentioned above provide a first-line defense system against oxidative stress. However, it is to be noted that if reactive oxygen species even in small amounts escape this first-line defense, it can lead to the formation of highly toxic and reactive products by triggering lipid peroxidation. Thus, another path is required to combat with this problem by providing a second line of defense which involves the enzymeglutathione $\mathrm{S}$ transferase that can reduce the phospholipid hydroperoxide and fatty acid hydroperoxide and ultimately terminate the cascade of lipid peroxidation (Sharma et al. 2004).

Another mode of defense against ROS is exhibited by the molecules that are non-enzymes and are basically of low molecular weight, for example, Vitamin $C$ (ascorbic acid), Vitamin E ( $\alpha$-tocopherol), $\beta$-carotene, glutathione, proline, phenolic acids, flavonoids, etc., while high molecular weight compounds are the secondary metabolites such as tannins and it is illustrated in Fig. 10. The low molecular weight non-enzyme antioxidant compounds play a great role in the growth and development of the plants as they can modulate not only the processes like cell division and cell elongation but also the senescence and death as they can interact with numerous components of the cell by functioning as redox-buffer (Foyer and Noctor 2005).

Medicinal plants contain flavonoids and phenolics that possess property to protect living organisms against the hazardous effect of ROS as they have strong freeradical scavenging potential and metal ions chelation properties (Govindarajan et al. 2005). C. speciosus is a very rich source of major antioxidant compounds such as phenolic acids, xanthones, tannins, lignans, flavones, ascorbic acid, $\beta$-carotene, $\alpha$-tocopherol, glutathione, and flavonoids (Devi and Urooj 2010). Studies show that these compounds not only defend against ROS but also provide protection from the breaking of DNA strands (Jha et al. 2010; Pai Kotebagilu et al. 2014). To date, various in vitro studies have been conducted on different parts of C. speciosus like roots, stems, and leaves that have evidently established the tremendous antioxidant potential. The relative solubilities of different phytochemicals are different and follow the basic motive behind the extraction, i.e., extraction done on the basis; whether the plant matrices contain polar, nonpolar compounds or have intermediate polarity, many different extracts like methanol, ethanol, petroleum ether, n-hexane, benzene, pure acetone, and acetone-water mixture have been used to isolate a diverse variety of active secondary metabolites from C. speciosus. Based on evaluative studies done using antioxidant analysis methods like total antioxidant scavenging activity, 1,1-diphenyl-2-picrylhydrazyl $(\mathrm{DPPH})$, nitric oxide scavenging activity, thiobarbituric acid, and 2,2'-azino-bis-3-ethylbenzothiazoline-6-sulfonic acid, it was reported that the antioxidant activity is mainly due to the phenolic contents present in different parts of the plant (Maji et al. 2020). In addition, the analysis of methanolic extracts of the rhizomes of C. speciosus showed the presence of various phytochemicals like steroids, glycosides, gracillin, methylprotogracillin, protogracillin, dioscin, methyl protodioscin, prosapogenin $\mathrm{B}$ of dioscin, diosgenin 3-O- $\beta-\mathrm{D}^{\prime}$ Glucopyranosyl, $(1 \rightarrow 3)-\beta$-glucopyranoside, and (Shrivastava et al. 2011). Furthermore, when assayed with DPPH and nitric oxide scavenging methods, methanolic extracts of $C$. speciosus showed much powerful nitric oxide and free radical scavenging activities as compared to the ascorbic acid (Jha et al. 2010). One of the reasons behind the 


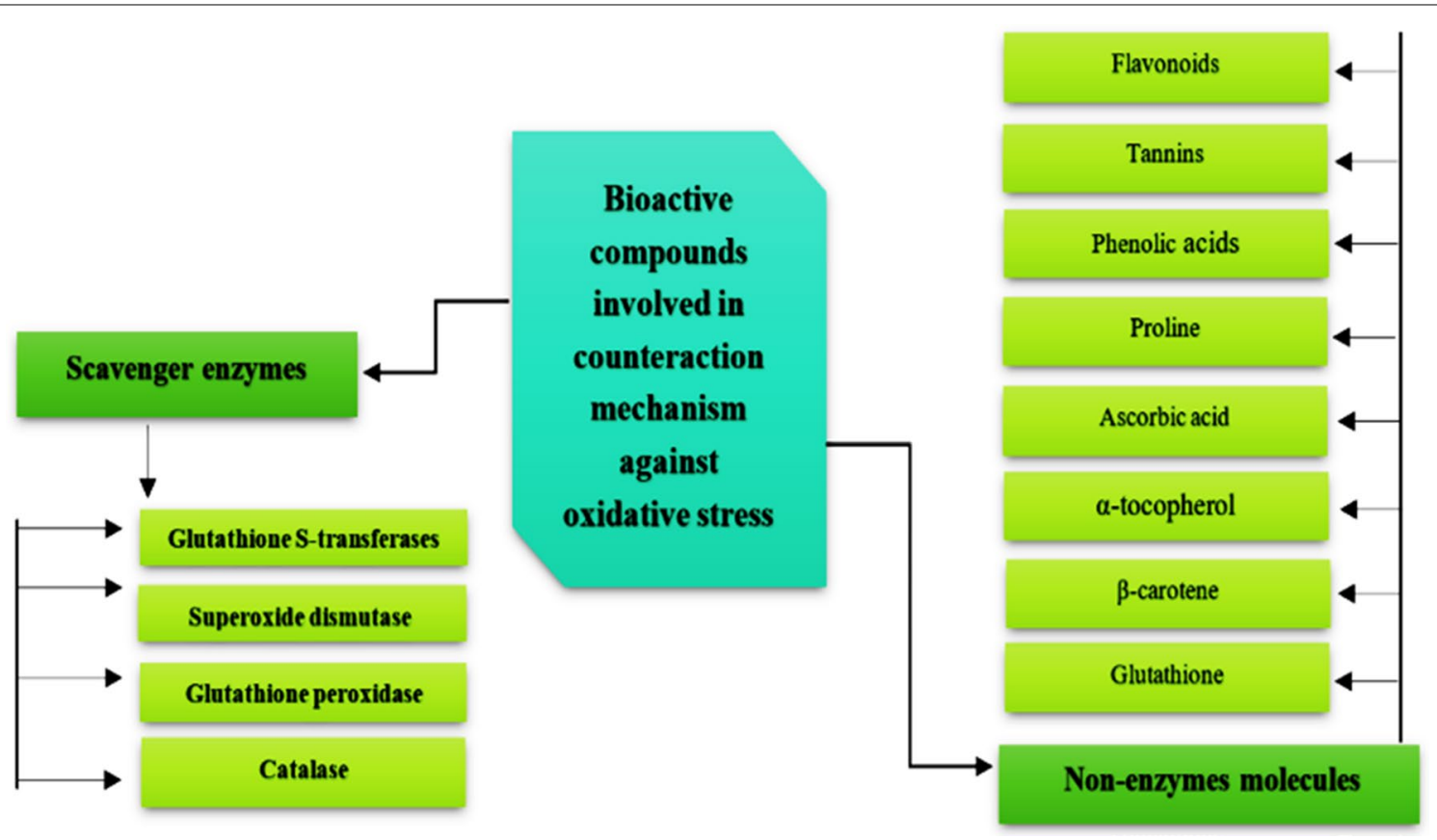

Fig. 10 Illustration of bioactive compounds involved in the counteraction mechanism against oxidative stress (Kasote et al. 2015)

antioxidative potential of the methanolic extract as suggested by the researchers is the presence of flavonoids, triterpenoids, glycosides, steroids, and tannins in $C$. speciosus (El-Far et al. 2018). Apart from the abovementioned solvents being used, chloroform extract of $C$. speciosus has also shown significant potency against free radical scavenging (Chakraborty 2009). Another study says that using the benzene extract of $C$. speciosus gives the best results, which is used against chronic diseases like heart disorders and cancers (Nehete et al. 2010). This might be due to the great dissolving ability of benzene for a diverse range of organic components because benzene in its ring structure contains the pi-clouds that allow them to interact with the pi-clouds of various solutes. Nowadays, more focus is on using the mixture of different solvents in appropriate ratios, which paves the way for the exploration of various unexplored phytochemicals to study their phytochemical and pharmacognostic potency. Work has been done in this direction which showed that when the extract of acetone water and acetic acid in the appropriate ratio was used against starch hydrolases (a member of glucoside hydrolase family, which needs to be inhibited in Type 2 diabetes), it exhibited a strong antioxidant property and inhibitory effect on the concerned enzyme (Lee et al. 2015). Antioxidant activity shown by different extracts of Costus speciosus is mentioned in Table 6.

Plant antioxidants when supplemented to animals have to go through many physiological and pharmacological changes, while getting absorbed, distributed, metabolized, stored, and then excreted out by the animal's body and also have to deal with several other factors such as their bioavailability, presence or absence of different transition metals, and co-antioxidant compounds. Therefore, parallel to the in vitro investigations, in vivo studies must also be undertaken, while they establish the therapeutic values of the bioactive components of the plants. Taking this into consideration, two pharmacologically significant chemical constituents, costunolide and eremanthin, of C. speciosus were orally administered in rats (streptozotocin-diabetic rats) through the in vivo method by an intragastric tube for two months. It was observed that there was a decline in the otherwise elevated level of thiobarbituric acid. However, in the brain, heart, kidney, pancreas, and liver, there was significant increment or elevation in the activities of superoxide dismutase, glutathione peroxidase, catalase, and in reduced glutathione content as shown in Fig. 11 (Eliza et al. 2010). Similarly, for the evaluation of antioxidative potential of C. speciosus, rhizomes of the plant were used as diet supplementation of Egyptian buffalo heifers for one month. Two groups were made in this study: One was that of control (no treatment was given, only basal diet), while the other was the group which was provided with the supplementation of C. speciosus rhizome. Comparative observations of both the scenarios revealed that the latter group of buffaloes showed up with the higher antioxidant potential of erythrocytes as was evinced by the total antioxidant 
Table 6 Antioxidant activity shown by different extracts of Costus speciosus

\begin{tabular}{|c|c|c|}
\hline Plant extract & Maximum antioxidant activity & References \\
\hline Chloroform extract & Free radical scavenging activity & Chakraborty (2009) \\
\hline Methanolic extract & Hydroxyl radical scavenging, Nitric oxide scavenging activity & Jha et al. (2010) \\
\hline $\begin{array}{l}\text { Acetone-water-acetic acid extract high oxygen } \\
\text { radical capacity }\end{array}$ & High oxygen radical absorbance capacity and free radical scavenging activity & Lee et al. (2015) \\
\hline Benzene extract & High total phenolic content and antioxidant activity & Nehete et al. (2010) \\
\hline
\end{tabular}

capacity improvement's significant decline in malondialdehyde (El-Far and Abou-Ghanema 2013). Though phytochemical analysis has been done on a significant level for this plant, there is a need to focus on the genetic and proteomics level as very little research has been done in this context.

\section{Hepatoprotective activity}

Among various deadly diseases, one of the common diseases that cause morbidity and mortality worldwide (around 2 million deaths every year) is liver disease (Asrani et al. 2019). Chemotherapeutic substances, various synthetic drugs, and toxic chemical compound like carbon tetrachloride $\left(\mathrm{CCl}_{4}\right)$ create toxic effects on the liver (Maheswari et al. 2008). To assess the hepatotoxic activities, there are certain serum biomarkers used, such as acid phosphatase, alkaline phosphatase, alanine aminotransferase, aspartate aminotransferase, and fluctuations in the level of these enzymatic biomarkers, which can be detected in the bloodstream as they get leaked out of the liver cells (Contreras-Zentella and HernándezMuñoz 2016). Serum hepatic biomarkers helping in the detection of hepatotoxicity are shown in Fig. 12.

The extract of the plant $C$. speciosus shows great potential for hepatoprotection as it contains phenolic compounds such as saponins, steroids, and glycosides (Verma and Khosa 2009; Devi and Urooj 2010). It has been evidently analyzed by using the extract of $C$. speciosus against hepatotoxicity caused by carbon tetrachloride in Swiss Albino mice. It was observed that the serum level of total protein, bilirubin, and hepatic biomarkers, which was increased due to the $\mathrm{CCl} 4$ intoxication, came back to their normal levels when the mice were given the methanolic extract of the rhizome of C. speciosus. These observations were compared with the reference standard drug silymarin, which is a hepatoprotective drug, and it was found that the potential of the extract had better effects in hepatoprotection activity (Bhuyan and Zaman 2008).

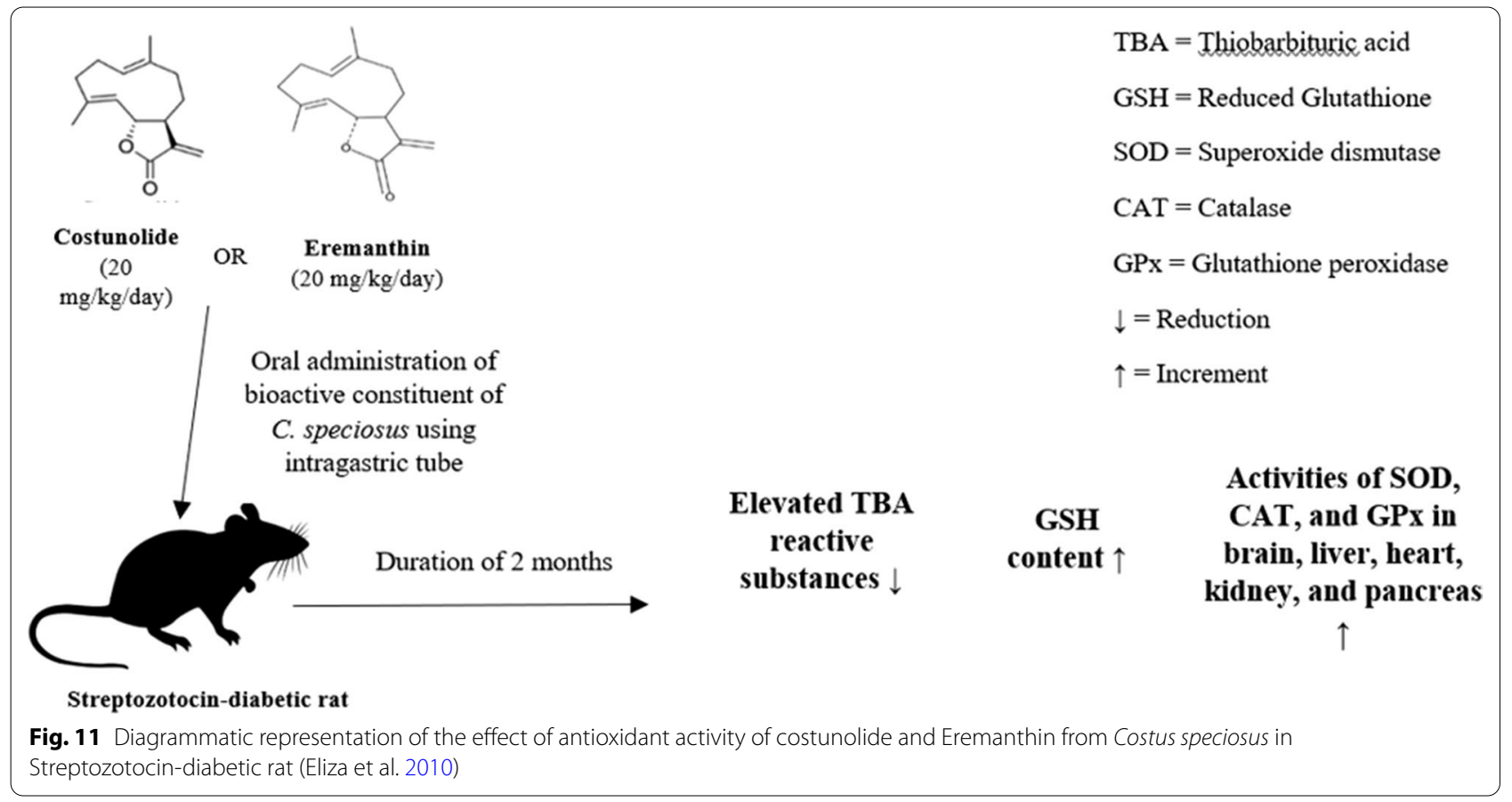


A similar study was conducted using the ethanolic extract of C. speciosus on Wister albino rats, and the results showed the potency of the plant against liver toxicity and their role as hepatoprotective agents (Verma and Khosa 2009). In the same context, a study was conducted on normal mice using very common, widely available, and accessible antipyretic and analgesic drugs, Paracetamol, which is otherwise safe but when overdosed can result in severe disorders like hepatotoxicity and nephrotoxicity (Hazai et al. 2001; Heard 2008). Damages caused to the liver by this drug are mainly driven by the depletion of the glutathione (a natural antioxidant found in the liver) by $\mathrm{N}$-acetyl-p-benzoquinoneimine (one of the metabolites of PA-liver damage) and lead to hepatocyte damage following the complete failure of the organ (Kulkarni 2013). Again, the increment in the serum levels of hepatic biomarkers (ALT, ALP, AST, and TNF $\alpha$ ) was used as indicators to assess the toxicity caused by the paracetamol in the liver, and it was found that the methanolic extract of C. speciosus successfully decreased the levels back to normal, which evidences its hepatoprotective potential (Kang 2013). It has been proved that alcoholic rhizome extracts of the plant contain hepatoprotective components having an antioxidant activity that helps in the reduction of ROS in the liver (Bhuyan and Zaman 2008; Devi and Urooj 2010; Eliza et al. 2010). An illustration of the brief mechanism of $\mathrm{CCl} 4$ and paracetamol toxicity in the liver is shown in Fig. 13 and Table 7. Still, there is a need to investigate and do more comparative evaluations of C. speciosus extracts on various other chemicals and drugs like vinyl chloride, aflatoxins, isoniazid, and arsenic that can cause injuries to the liver and to establish the use of the plant as a source of a potent drug, extensive studies must be done on humans to confirm their hepatoprotective activity on them.

\section{Anticholinesterase action}

Anticholinesterase activity or cholinesterase inhibitory activity is shown by the chemicals that can prevent the neurotransmitter breakdown and thus lead to their accumulation in the synaptic cleft. The activity of these neurotransmitter compounds plays an important role against various neurological disorders such as Alzheimer and myasthenia gravis. In the recent arena of research, more focus is now being given to the plant sources that show similar or higher potential regarding the anticholinesterase action. In this regard, work done by Bhattacharya et al. (1972) gives evidence that the alkaloids isolated from the plant C. speciosus show considerable anticholinesterase activity when tested on the blood pressure of a dog and frog's rectal muscle (Maji et al., 2020). The alkaloids present confer the plant with anticholinesterase activity that also contributes as a depurative agent and in the treatment of eye diseases (Mishra et al. 2009). However, to specifically identify the individual alkaloids behind this activity, a lot more research work is needed to be done in the areas of selective screening and study of mechanisms involved.

\section{Diuretic activity}

The diuretic potential of $C$. speciosus has been reported to be used traditionally, but to explore its scientifically driven proofs, experiments have been done on Wistar albino rats using different extracts of the plant such as

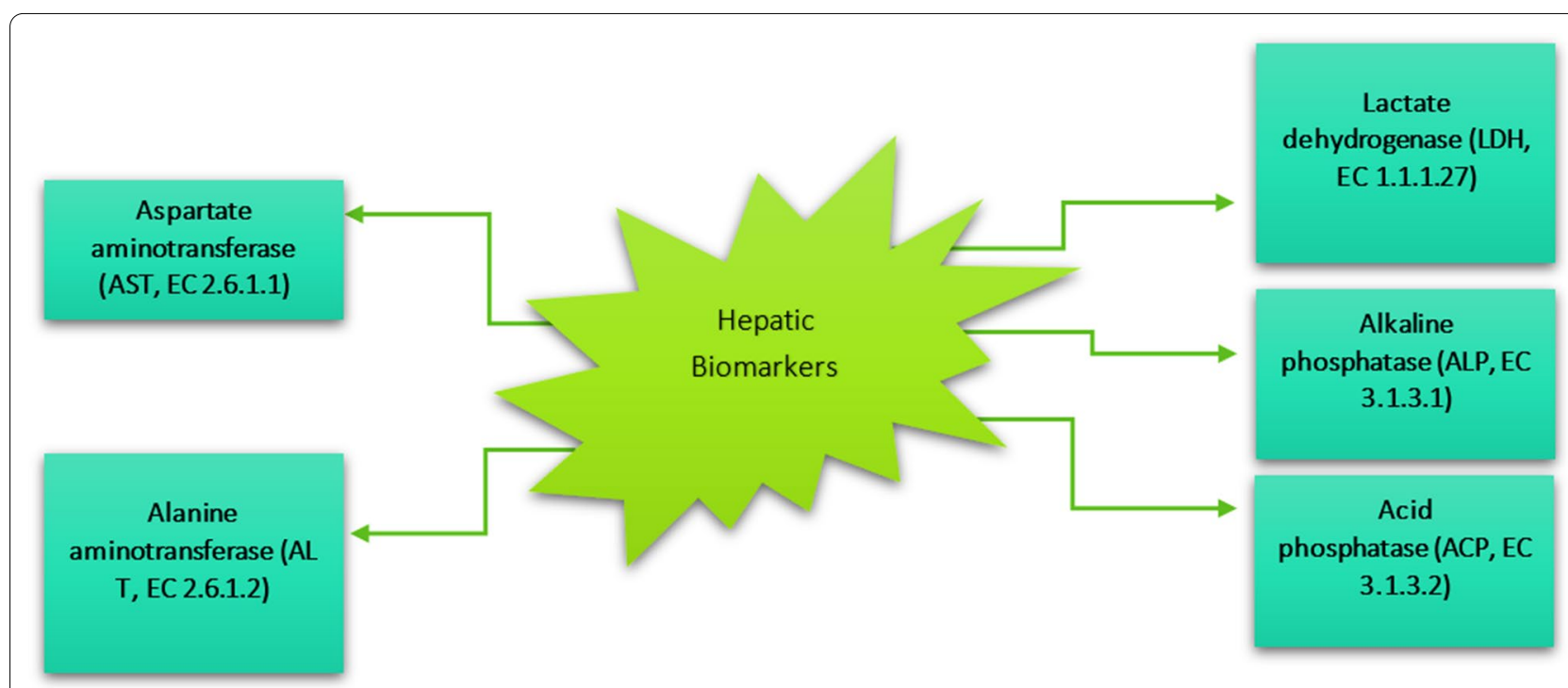

Fig. 12 Hepatic biomarkers which help in detecting hepatotoxicity (Contreras-Zentella and Hernández-Muñoz 2016) 


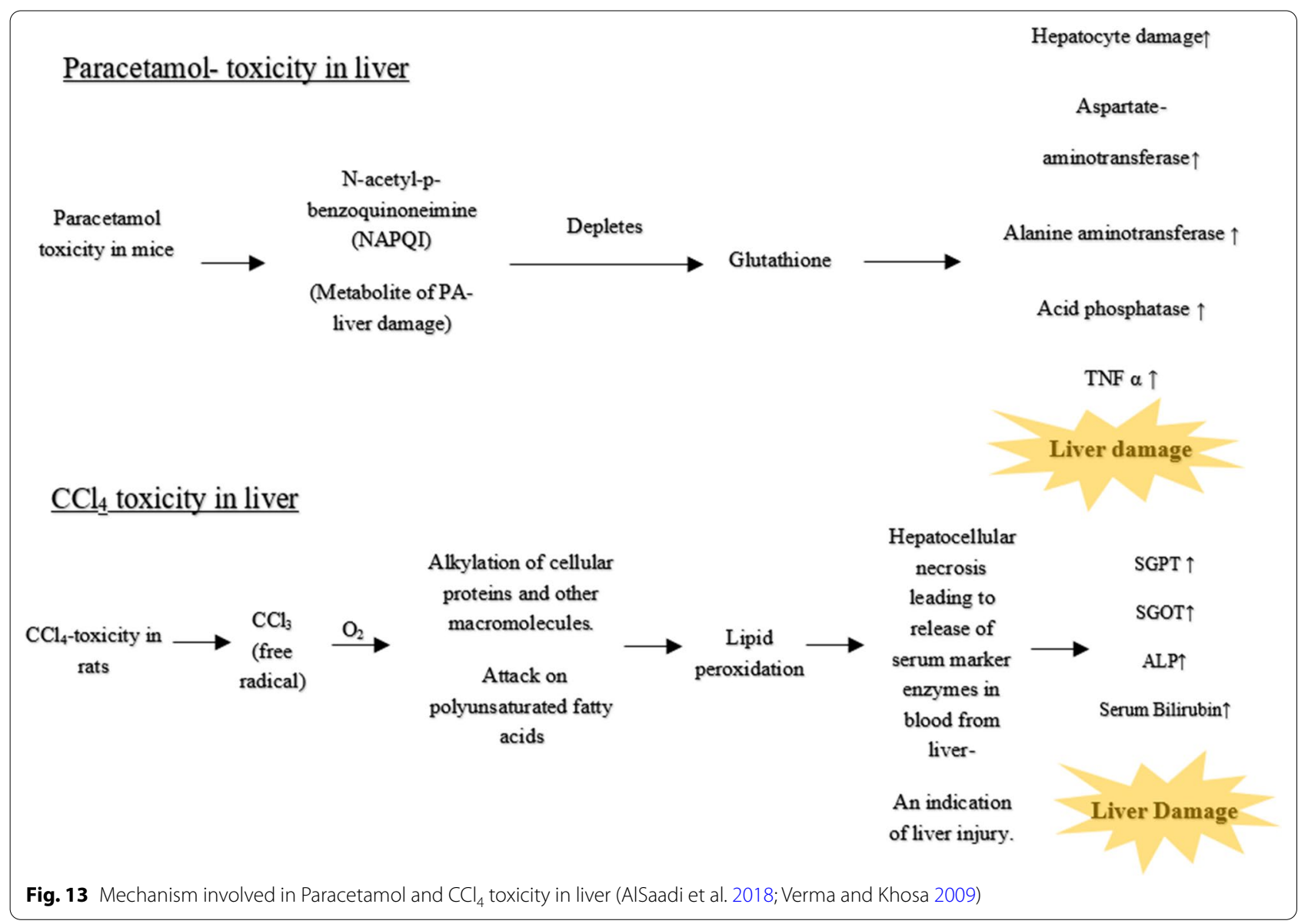

leaves and rhizomes. The activity of the aqueous and ethanolic extracts of the plant was compared by the activity of Furosemide diuretic drugs used commercially to treat various disorders like serious kidney problems, edema, and high blood pressure (Consumer Medicine Information-News Medical Life Sciences 2019), and it was found that the volume of the urine and diuretic index significantly increased. One more interesting observation was that the saluretic action of the plant extract was weaker than the Furosemide loop drug as there were lesser electrolyte secretions. However, there is a requirement to study the effects of diuretic responses of higher doses of the extracts to establish the exact mechanism of the action (Dubey et al. 2010; Prabhu et al. 2014).

\section{Estrogenic activity}

To study the activity of the plant of $C$. specious concerning its estrogenic action, the extract of the rhizome was given to rats and it was found that there was a stimulatory effect on the uterus (Lijuan et al. 2011). Another study was done on adult female mice using the methanolic extract, which revealed that the weight of the uterus increased; however, there was a decline in the weight of ovaries (Choudhury et al. 2012). There was also an increment in the concentration of glycogen and production of proliferative changes in the tested rats' uterus. It was explained that this activity is the attribution of the saponin content present in the plant (Rastogi and Mehrotra 2004a, b). This portion still requires a lot of studies to be done by using different extracts of the plant to explore various other changes in the uterine activities due to the estrogenic actions of the plant.

\section{Antispasmodic activity}

The antispasmodic or spasmolytic activity of any compound refers to its ability of the prevention of spasm or provides relief against the spasm caused particularly in involuntary muscles. A different extract of C. speciosus has been tested on the ileum of a guinea pig by Banerji et al. (1982). The results obtained proved that the plant has moderate levels of spasmolytic activity. When the activity of the C. speciosus extract and conventionally used antispasmodic drug papaverine was compared, it was found that the former showed weaker antispasmodic properties (Srivastava et al. 2011). 


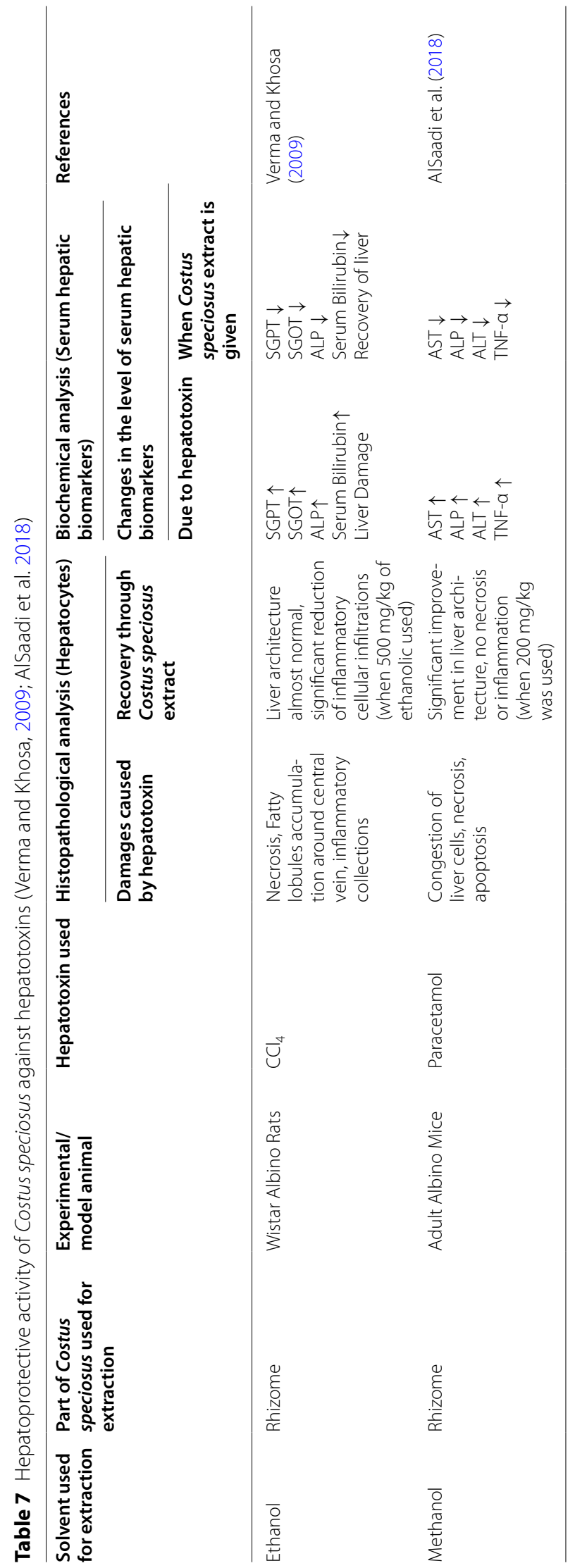




\section{Antifungal activity}

To study the antifungal activity of $C$. speciosus studies, a technique like a column chromatography has been used, which reveals that the antifungal property was due to the presence of sapogenins and saponins (Bandara et al. 1989). Various antifungal compounds such as saponin ( $B$ and $C$ ) and tigogenin have been investigated against fungi Botrytis cinerea, Curvularia sp., Alternaria sp., Sclerotinia sclerotiorum, and Fusarium lini. These compounds were found to be effective against the germination of conidia. Another study conducted by Duraipandiyan et al. (2012) proved the antifungal properties of the plant by using different extracts such as methanol, chloroform, and ethyl acetate. The inhibitory action of the extracts has been tested against fungi Curvularia lunata, Scopulariopsis sp., Epidermophyton floccosum, Trichophyton spp., Magnaporthe grisea, and Aspergillus niger, and it was reported that the phytocomponents like eremanthin and costunolide were responsible for this (Maji et al. 2020). Antifungal activity of C. speciosus has been tested against a wide range of fungi, which is shown in Fig. 14. Furthermore, the antifungal activity of Costus speciosus can also be evinced through the research work done by Sulakshna and Rani (2015) where it has been observed that the diameter of the inhibition zone of different fungi increases as the concentration of the prepared stock solutions (with 0.5-2 mg of plant extract) made by using dimethyl sulfoxide, DMSO as solvent, was increased and is shown in Fig. 15.

\section{Anthelminthic activity}

One of the most common and serious threats to human health is the problem of worm infestation. Infections caused by the worms, particularly parasitic worms, have chronic effects on human health. Methanolic and aqueous extract of the C. speciosus' aerial parts has been studied against one of the most common and widely spread worms Pheretima posthuma (adult earthworm) (Srivastava et al. 2011). Also, comparative studies were done using the conventional antiworm medication, Albendazole, which is reported to cause paralysis and death of the worm by causing expulsion of the worms as the conductance of the chloride ion gets increased in the membrane of the muscles of the worm and thus there occurs flaccid paralysis due to reduction in excitability and hyperpolarization in the muscles (Borkar et al. 2010). Through these studies, the traditional claims of anthelminthic potential of $C$. speciosus have been proved as the aqueous and the methanolic extract showed greater potency against the worm than the standard drug, albendazole (Borkar et al. 2010). It is also noteworthy that the aqueous extract was more effective in antiworm activity than the methanolic extract (Fig. 16). Though the available literature shows studies conducted on the common earthworm, it is believed that this leads the path to explore this activity of other harmful parasitic worms as there is a resemblance in the physiology and anatomy of Pheretima with other intestinal worms that cause infections in human beings (Srivastava et al. 2011). Moreover, there is a need to trace the exact mechanism of the anthelminthic activity and

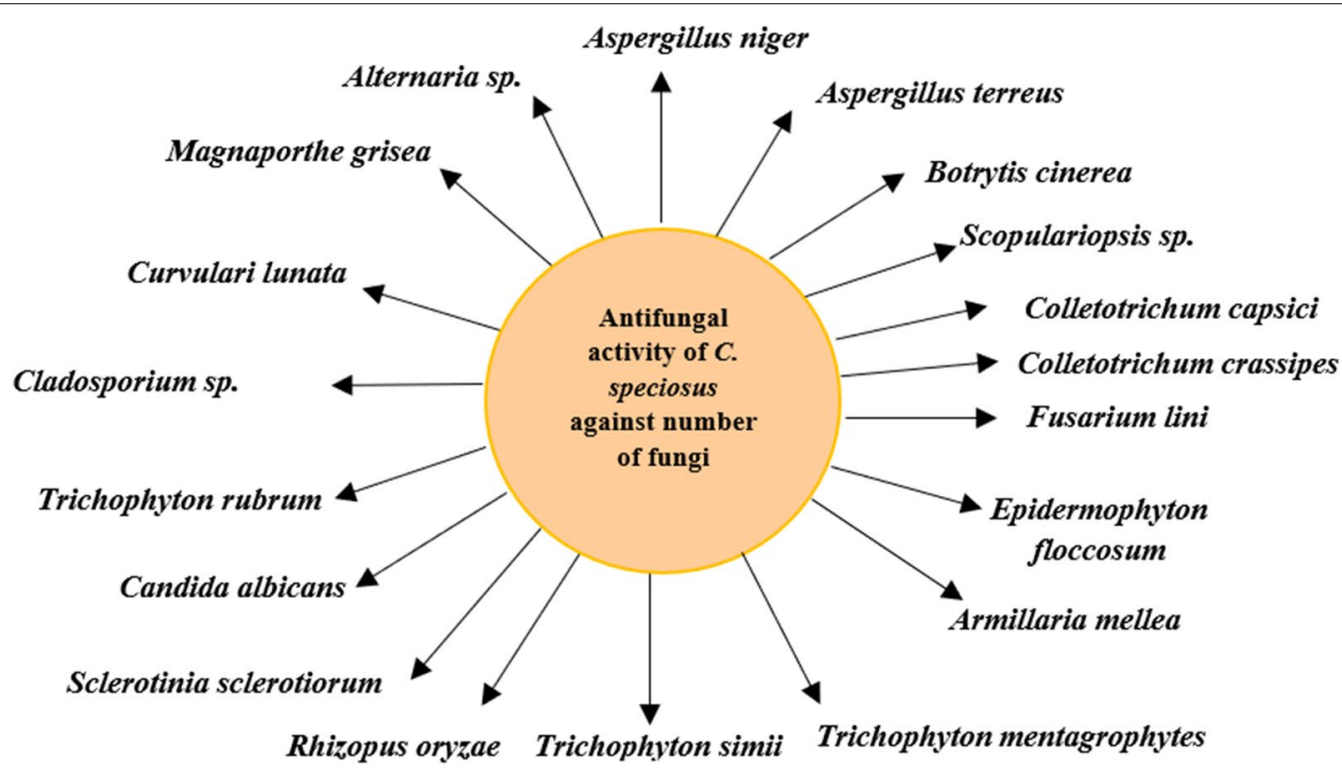

Fig. 14 Antifungal activity of Costus speciosus against number of fungi (Duraipandiyan et al. 2012; Maji et al. 2020) 


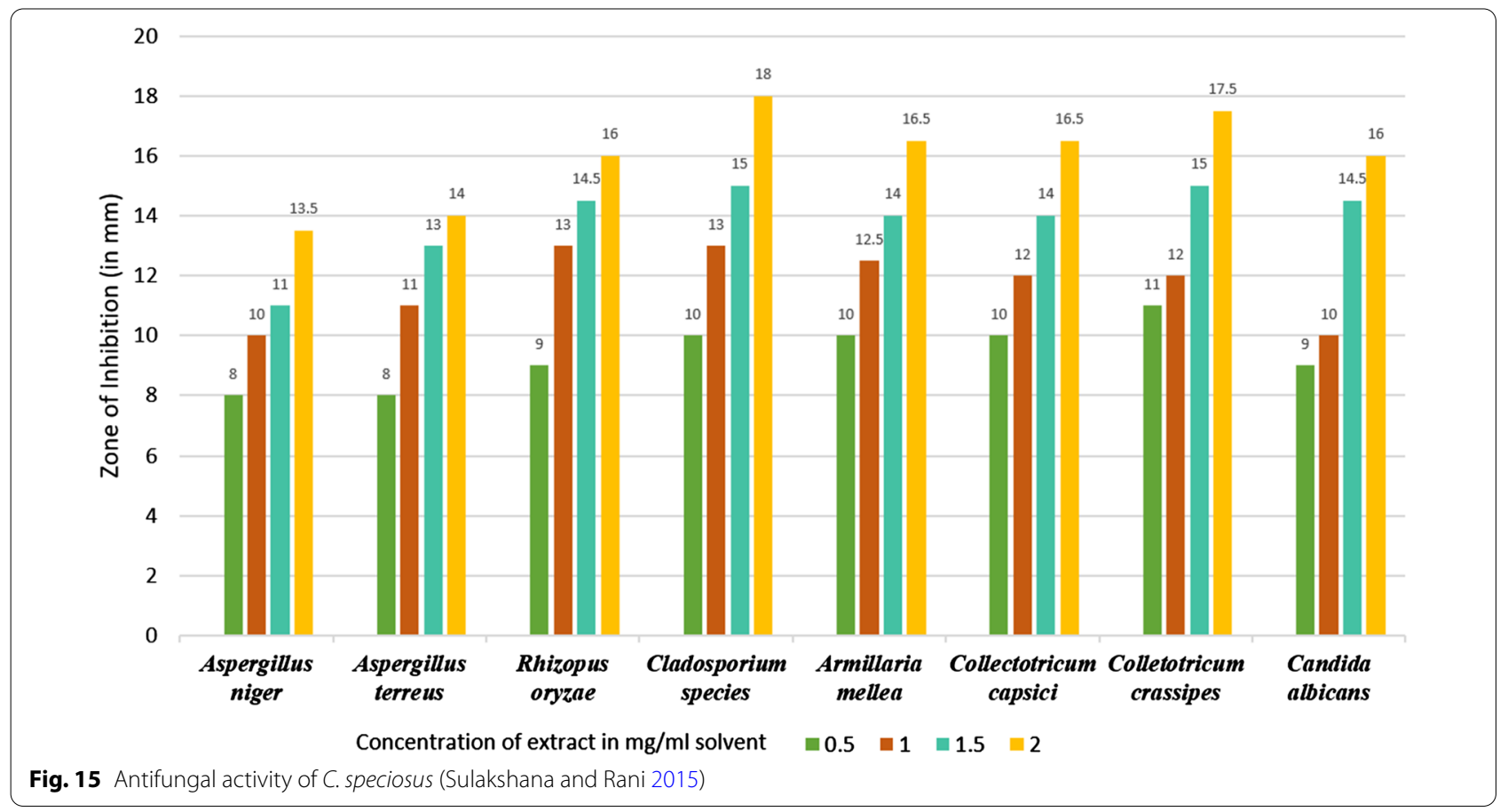

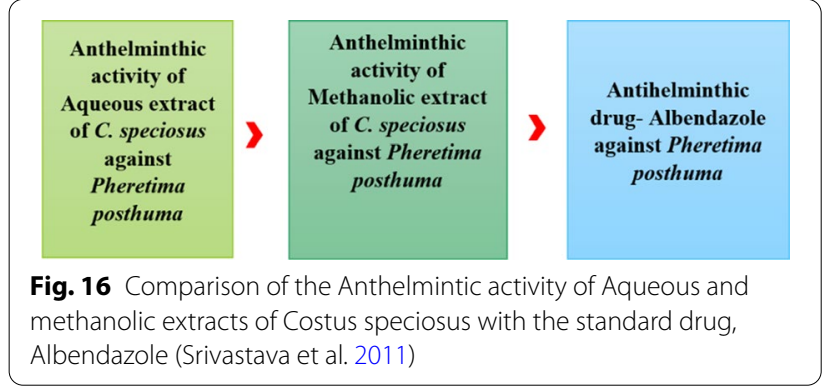

accountable phytoconstituents of C. speciosus involved in this activity.

\section{Antibacterial activity}

Increasing undesirable side effects of synthetic drugs used as antibiotics has grabbed the attention of the scientists to search for more and more herbal resources that would be employed as replacements for these antibiotics. The rhizomes and leaves of C. speciosus are known to possess a wide variety of compounds that have antibacterial properties. Extensive research done in this context has validated the traditional use of this plant against bacterial infections. In vitro studies were performed by Malabadi (2005) and Sulakshana and Rani (2013) against bacteria such as Staphylococcus aureus, Salmonella, Bacillus subtilis, Shigella, Klebsiella pneumoniae, Pseudomonas, and Escherichia coli using aqueous, hexane, and methanolic extracts of C. speciosus (Shrivastava et al. 2011). By employing the disc diffusion method, another evaluative study was conducted by Arunprasath and Gomathinayagam (2014) using the methanolic and hexane extracts of $C$. speciosus and proved the antibacterial potential of the plant against Bacillus subtilis, Shigella sp., Escherichia coli, and Staphylococcus aureus. Besides rhizome extract, the leaves of the plant also possess antimicrobial properties as was shown in the studies were done by Vaidya Shingadia (2020), where it was found that among many different fungi, viz. E. coli, Staphylococcus aureus, Streptococcus pyogenes, Pseudomonas aeruginosa, Bacillus subtilis, being tested, by using the extract of the leaves of $C$. speciosus, the maximum zone of inhibition (measured in terms of the average diameter of zone inhibition in millimeters), which is the represents the antimicrobial activity, was shown by E. coli and lowest activity by Streptococcus pyogenes. It is believed that the alkaloids such diosgenin might be responsible for such antibacterial properties exhibited by the plant (Ariharan et al. 2012). However, to explore the potential of the plant as bio-medicine and bio-bactericide, more biotechnological approaches should be made.

\section{Anticancer activity}

According to the World Health Organization (2018), cancer is reported to be one of the deadliest diseases, causing 
deaths of around $70 \%$ of the population globally, and holds the position of the second leading cause of death in the world. Plant-derived drugs are now being focused as the complementary source of medicine to cure cancer, and it has been shown in studies also those herbal medicines when used in combination with the regular therapeutic drugs show advantageous effects on cancer patients' immune modulation, survival, and quality of life (Yin et al. 2013). Various in vitro and in vivo studies have been done on the phytochemistry of C. speciosus, revealing the presence of some active compounds like Costunolide, Beta-amyrin, Camphene, Lupeol, Zerumbone, Alpha-humulene, and Diosgenin, which shows significant anticancer potential. To combat cancer, there are various up-regulatory and down-regulatory mechanisms that are being followed by these compounds (El-Far et al. 2018), shown in Fig. 17A and B. One of the up-regulatory mechanisms against cancer is through the activity of tumor suppression in which the transcription factor $\mathrm{p} 53$ plays a very crucial role as it is known to promote various anticancer activities as the promotion of genes that causes growth arrest (genes of p21) and ultimately inhibits the proliferation of cancerous cells, induction of ROS, and regulation of apoptotic pathways. The active components of $C$. specious have been studied to investigate their activity against various cancers in humans like lung cancer, osteo carcinoma, melanoma, and cervix carcinoma (ElFar et al. 2018). The extracts of different parts of the plant have been evaluated for their anticancer potential; for example, methanolic, hexane, and ethyl acetate extract of the rhizome showed significant antiproliferative activities against human colon cancer (Baskar et al. 2012). Similarly, when the methanolic extract of the leaf was tested, it was found that there was a reduction in the viability of cancerous cells (Nair et al. 2014). It was reported that the extract of the plant by an increase in the activities of caspase-3 leads to the disturbances in the cell cycle. A bioactive ingredient, Costunolide, which is found significantly in C. speciosus, shows the capability to arrest the cells involved in cancerous activities particularly at their second growth phase and mitotic phase. In addition to this, costunolide also affects the regulation of NF-k $\beta$, the overexpression of which must be prevented; otherwise, the cancerous cells would continue their proliferation and cell survival will be maintained (El-Far et al. 2018). It has been reported by Pitchai et al. (2014) that the downregulation of these NF-k $\beta$ (if they are over-expressive) can be done by using Costunolide obtained from C. speciosus and its activity has been testified against human breast cancer. Furthermore, it has been seen that the initiator caspase (e.g., caspase-9) and executioner caspase (like caspase-3) both get overexpressed or their activity was significantly increased, which is needed to destroy cancer cells because these endo-proteases lead the cell to apoptosis (Roy and Manikkam 2015). In the same way, diosgenin, another very important anticancer compound produced in the C. speciosus, also shows the apoptotic activity as it actively participates in increasing the DR-4 levels and endo-proteases (like caspase-3), and this property has been studied against human breast adenocarcinoma with cell line-MCF-7 and human liver cancer (cell line HepG2) where cytotoxicity was observed (ElFar et al. 2018). Detailed illustration of anticancer activity of costunolide present in Costus speciosus is shown in Figs. 18 and 19.

\section{Anti-inflammatory activity}

Costus speciosus has been used by traditional folk for ages to treat various inflammatory disorders like bronchitis, fever, rheumatism, and headache. Bioactive components like diosgenin and costunolide have been exploited against various inflammatory diseases as they are known to potentially inhibit the activity of tumor necrosis factoralpha (TNF- $\alpha$ ), a cytokine, which is released in response to infection as an alarm for other immune reactions to occur and leads to the inflammation of the concerned tissues or cells. Evaluation of the anti-inflammatory property of diosgenin isolated from C. speciosus was done on RAW 264.7, a macrophage, and it was observed that there was an inhibitory or suppressive effect on the virus and the activity of diosgenin was found similar to the MTX (methotrexate), a commonly used immune system suppressant (Selim and $\mathrm{Al}$ Jaouni 2016).

Besides diosgenin, costunolide also shows inhibitory potential against TNF- $\alpha$, cyclooxygenase, and interleukins by following the mechanisms like protein kinase pathways activated by mitogen and inhibiting NFk- $\beta$ in the activated microglia (Rayan et al., 2011). Various other bioactive chemical compounds like dehydrodihydrocostus lactone, reynosin, arbusculin A, santamarine, and stigmasterol isolated from C. speciosus' chloroform extract have been studied on the isolated mononuclear cells of the blood to possess anti-inflammatory activity by inducing the reduction in the levels of various interleukins (such as interleukins 1 and 6), prostaglandins TNF- $\alpha$ (Al-Attas et al. 2015).

\section{Antidiabetic activity}

According to the report of the National Diabetes and Diabetic Retinopathy Survey (2019) done by the Health and Family Welfare Ministry of the Government of India, the prevalence of diabetes was recorded to be $11.8 \%$. In another report published by the International Diabetes Foundation (IDF) Diabetes Atlas India (2019), alarming figures have emerged, which shows that there are around 77 million diabetes patients present, which compels the 
$\mathbf{A}$

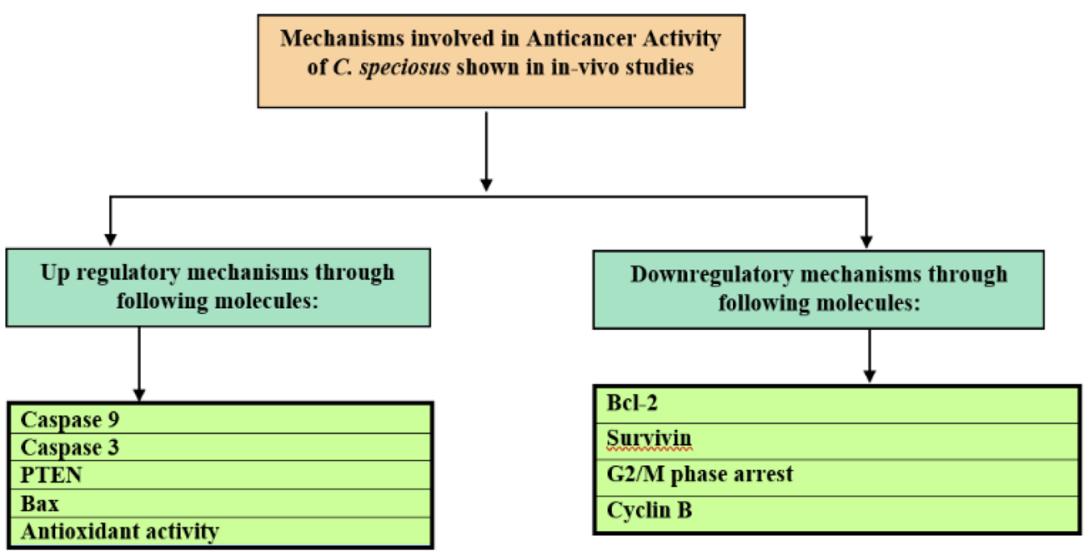

$\mathbf{B}$

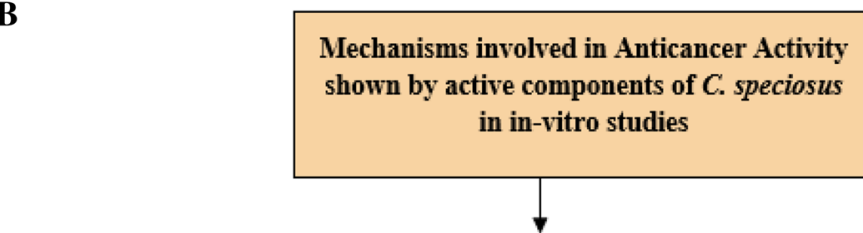

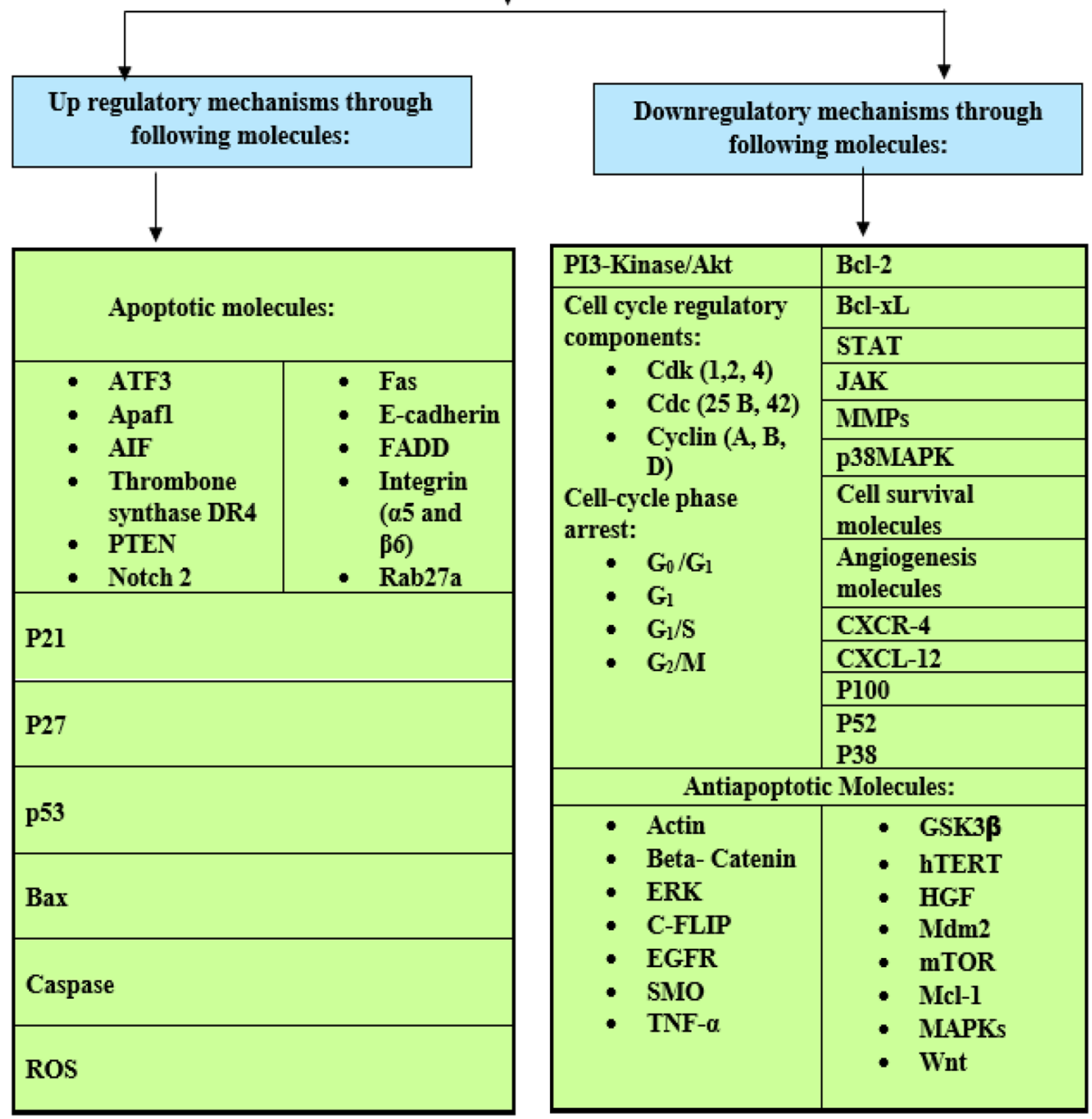

Fig. 17 A Mechanism involved in anticancer activity of Costus Speciosus in in vivo studies which includes up-regulation of various molecules (El-Far et al. 2018). B Mechanism involved in anticancer activity shown by active components of Costus speciosus in in vivo studies (El-Far et al. 2018) 


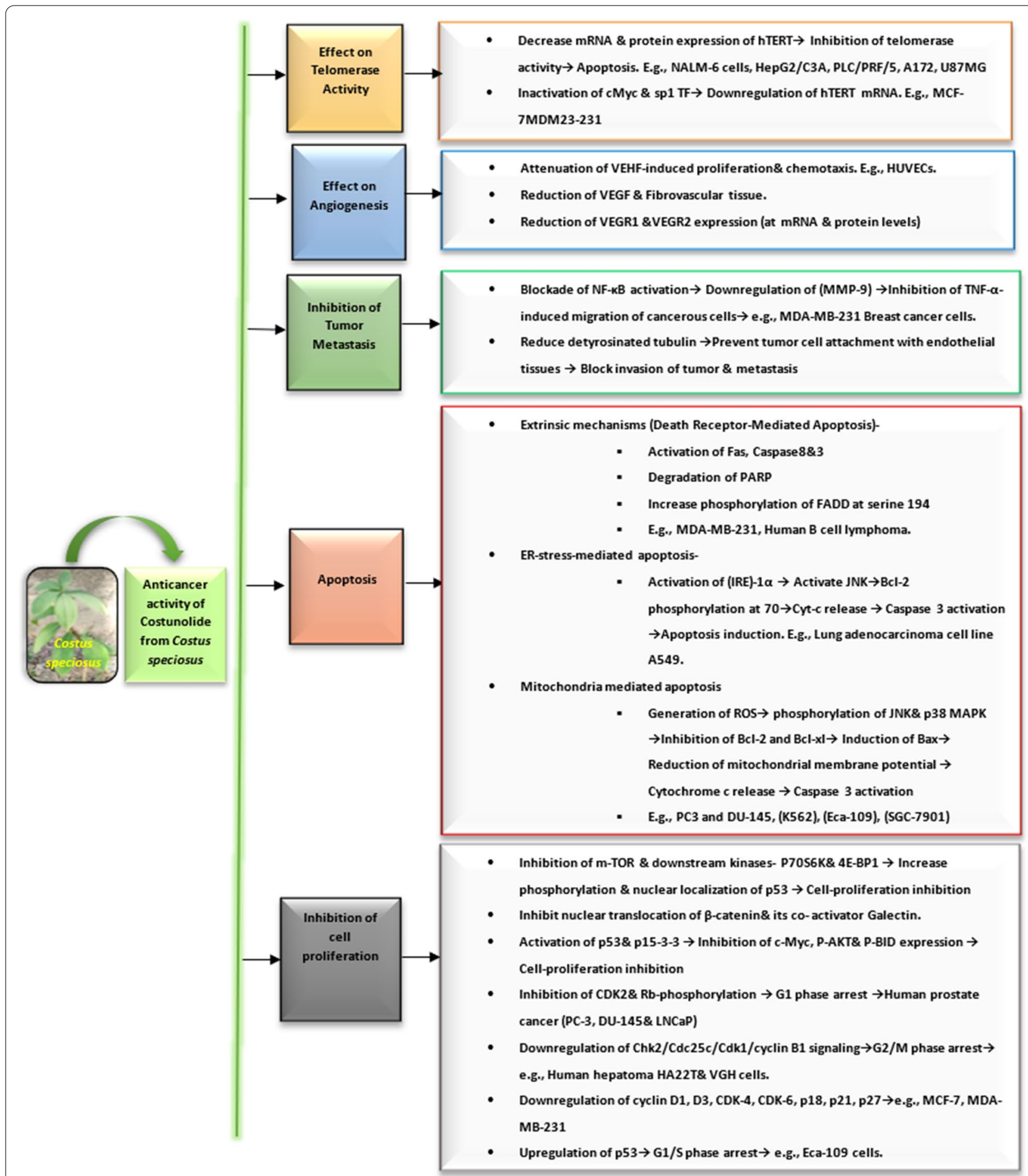

Fig. 18 Detailed illustration of anticancer activity shown by Costus speciosus (Kim and Choi 2019)

country to make some re-evaluations and formulate some effective strategies to fight the disease as the numbers are continuously rising and it has been estimated by IDF that in the next 25 years, this number will increase to over 134 million. Apart from creating several health hazards, this disease takes approximately $10 \%$ of the global health expenditure, which is quite a big figure in itself to 


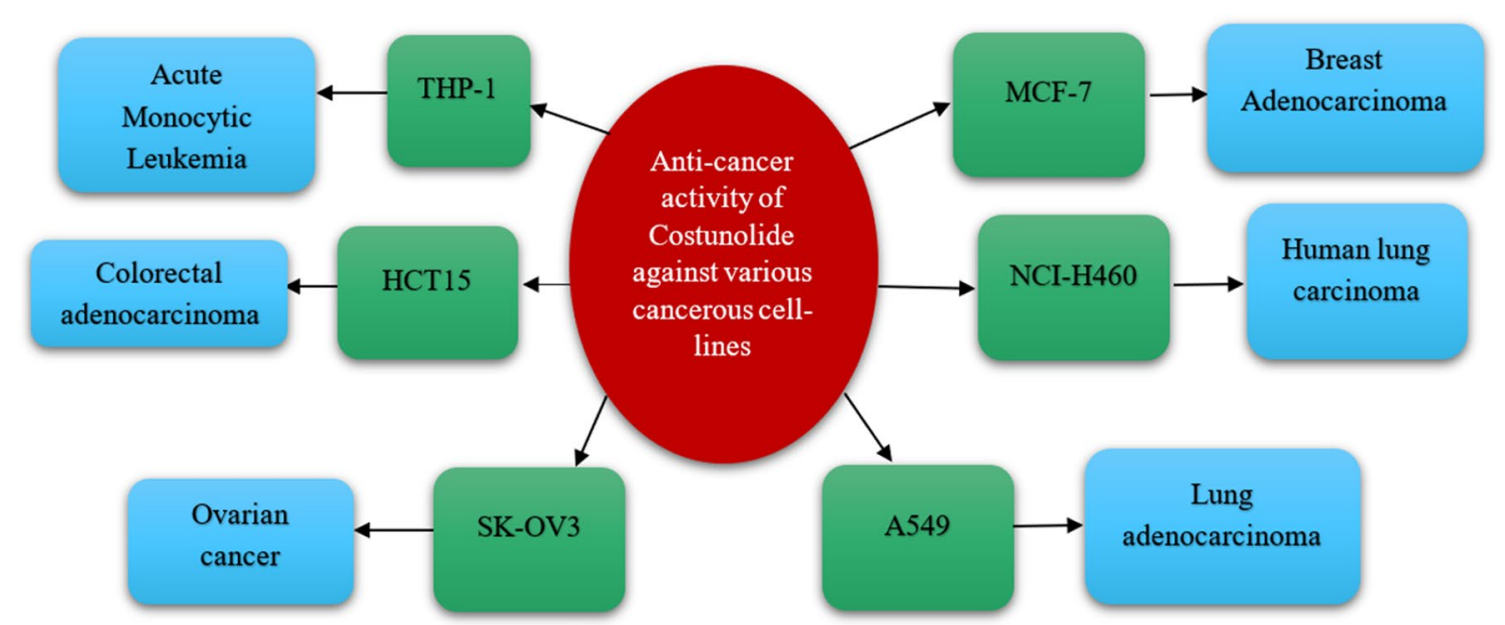

Fig. 19 Diagrammatic representation of anticancer activity shown by Costunolide against various cancerous cell-lines with associated cancers (El-Far et al. 2018; Maji et al. 2020)

draw the attention of the scientists to explore both more herbal and cost-effective remedies of the disease.

Diabetes mellitus is a disease in which the glucose level in the blood gets increased because of the relative or absolute deficiency or insufficiency of the insulin in the blood. Reflecting the level of glucose in the blood, three conditions are noteworthy while mentioning diabetes-Normo-glycemic, hypoglycemic, and hyperglycemic conditions showing normal, below normal, and too high level (above normal) of glucose in the bloodstream, respectively. For the treatment of diabetes, several drugs like insulin, biguanide, thiazolidinediones, and sulfonylureas are commonly used. Besides these drugs, several medicinal plants are exploited to gain remedies for the disease. Among such medicinal plants is the C. speciosus that exhibits significant antidiabetic properties and is given the name "insulin plant" as a very important antidiabetic agent Diosgenin is found in them (Rani et al. 2012; Sulakshana and Rani 2015). To investigate the antidiabetic potential of $C$. speciosus, an experimental study was done by Daisy et al. (2008) on male diabetic rats that were induced by streptozotocin causing them to develop hyperglycemia. It was observed that when such diseased rats were administered with methyl acetate extract, hexane extract, and methanolic extract for about 60 days, there occurred a significant reduction in the levels of glucose in the blood plasma as compared to the control group. Among these three extracts, the highest antidiabetic potential and hypoglycemic activity were shown by hexane extract. In addition to this, total cholesterol, glycosylated hemoglobin, and cholesterol level were also decreased (Daisy et al. 2008). A similar study was conducted on male rats induced by Alloxan, and the antioxidant, antihyperlipidemic, and antihyperglycemic activities of the ethanolic extract of $C$. speciosus were tested and compared with glibenclamide (a standard drug), and results showed that there was a tremendous decrease in blood sugar concentration, which may have occurred due to a decrease in gluconeogenesis and increase in glycogenesis. Moreover, the activity of antioxidant enzymes present in the liver was also found to be improved along with the decrease in cholesterol, plasma lipids, and triacylglycerol (Mosihuzzaman et al. 1994). There are the other numbers of investigations done by various workers to evaluate the anti-diabetic potential of $C$. speciosus and alterations caused in the biochemistry of the treatment group; for example, $\alpha$-glucosidase and $\alpha$-amylase were inhibited by the leaf extract (methanolic extract) of the plant, which ultimately leads to the decrease in the plasma protein glycation by delaying the digestion of carbohydrate and decreasing the absorption of glucose (Perera et al. 2016). Other studies revealed that the antidiabetic component, costunolide, has a stimulatory effect on the beta cells that led to the secretion of insulin (Eliza et al. 2009). Various effects of active constituents like eremanthin and costunolide derived from $C$. speciosus are shown in Fig. 20.

\section{Conclusions}

In this review article, efforts have been made to throw light on the medicinally important plant $C$. speciosus with regard to its ethnobotanical, phytochemical, and pharmacological properties. The plant exhibits strong antioxidant, anti-inflammatory, anticancer, anticholinesterase, hepatoprotective, diuretic, estrogenic, antispasmodic, antifungal, and 
antibacterial properties that are due to the presence of phytoconstituents like stigmasterol, $\beta$-sitosterol, campesterol, gracillin, dioscin, diosgenin, sesquiterpenes ( $\alpha$-humulene, zerumbone, dehydrodihydrocostus lactone, and dehydrocostus lactone), terpenoids (cycloartenol, $\beta$-amyrin, lupeol, and $\alpha$-amyrinsterate), and sesquiterpene lactones (costunolide, eremanthin, arbusculin $\mathrm{A}$, and santamarine). The unique secondary metabolites like diosgenin and costunolide exhibit strong antidiabetic properties. The former reduces the blood glucose level by inhibiting gluconeogenesis and promoting glycogenesis by adversely affecting the activity of the enzymes $\alpha$-glucosidase and $\alpha$-amylase, while the latter stimulates the $\beta$ cells of islet of Langerhans of the pancreas to secrete insulin. Thus, the extract of the plant can be utilized as an effective carbohydrate metabolizer that smoothens the level of glucose in diabetic patients. The anticancerous compound costunolide and its derivatives act as a mitogen arrest factor, reducing the viability of cancerous cells by increasing the activity of caspase- 3 and regulating the overexpression of necrosis factor. Besides, it is recommended that the estrogenic properties of the plant must be deeply explored which would contribute to the field of endocrinology. In addition to these pharmaceutically significant secondary metabolites, plants contain other metabolites like santamarine, stigmasterol, and arbusculin A having effective anti-inflammatory and antioxidative action. Due to the presence of strong antioxidant phytoconstituents like gracillin, methylprotogracillin, diosgenin 3-O- $\beta-\mathrm{D}^{\prime}$ Glucopyranosyl, protogracillin, methyl protodioscin, dioscin, prosapogenin $\mathrm{B}$ of dioscin, $(1 \rightarrow 3)$ - $\beta$-glucopyranoside, it is declared that the plant could be employed against various diseases as it would efficiently assist both first and second line of defense of an organism. Furthermore, it is quite evident from this review that the extract of these plants can serve as a better replacement for many commercial drugs like glibenclamide, albendazole, silymarin, etc. However, it is worth mentioning that phytochemistry, pharmacology, and pharmacognosy of C. speciosus in the crude form have been well studied by researchers, but more effort is needed regarding in vivo studies on humans and authentic marketed formulations of this

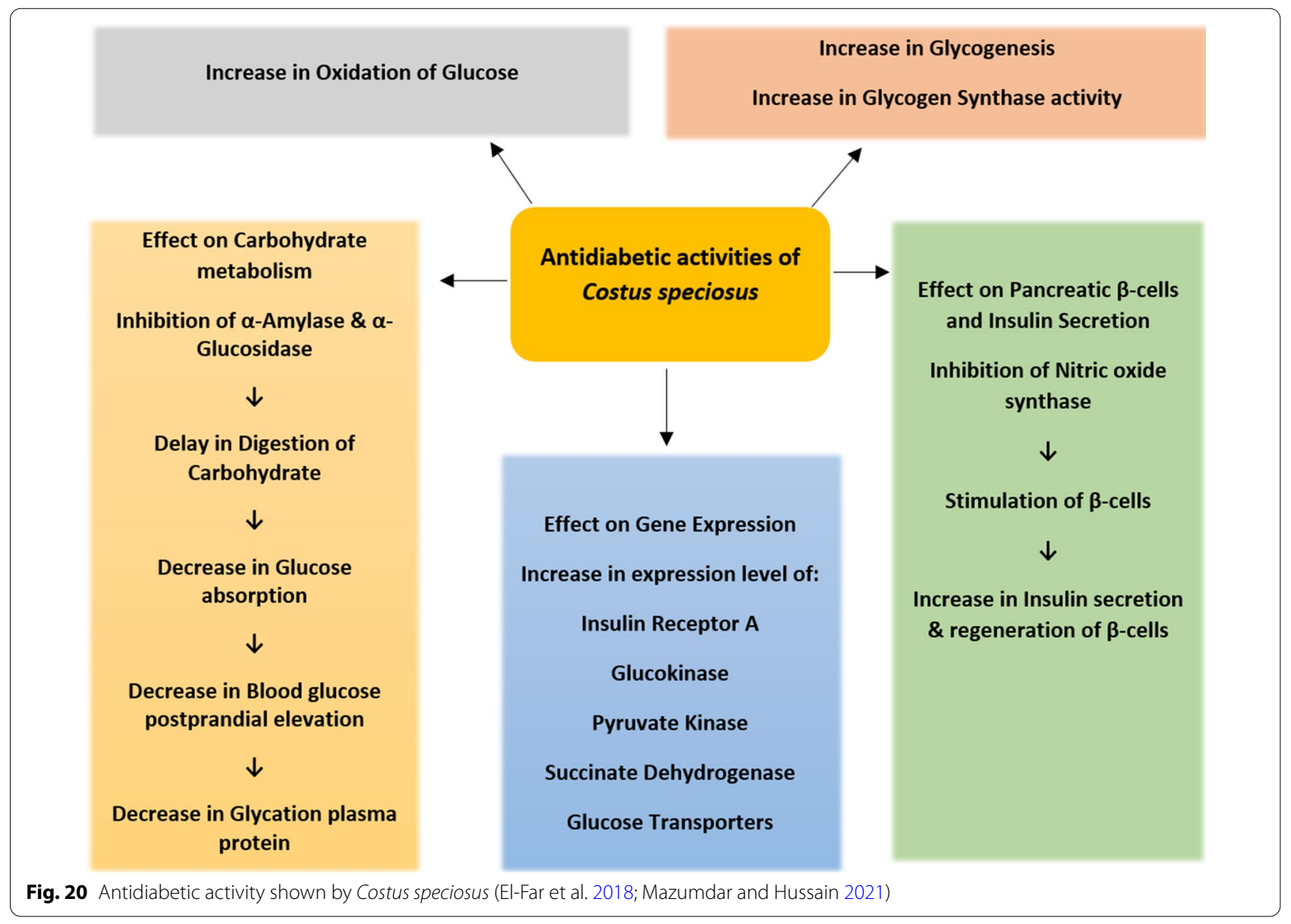


plant. Thus, C. speciosus can be exploited as an economically sustainable source of effective drugs against deadly diseases like diabetes and cancers with less or no side effects, and further research is needed to explore the intricacy of its pharmacological actions with human trials.

\begin{abstract}
Abbreviations
GC: Gas chromatography; MS: Mass spectrometry; UPLC: Ultra-performance liquid chromatography; ESI-MS: Electrospray ionization-tandem mass spectrometry; NMR: Nuclear magnetic resonance; ATF: Activating transcription factor; Apaf1: Apoptosis inducing factor 1; FADD: Fas-associated protein with death domain; PI3-K: Phosphatidylinositol 3-kinase; Akt: Ak strain transforming; Cdk: Cyclin-dependent kinase; Cdc: Cell-division cycle; Bcl: B-cell lymphoma; JAK: Janus kinase; MMPs: Matrix metalloproteinases; MAPK: Mitogen-activated protein kinases; CXCR-4: $C X C$-chemokine receptor 4; $C X C L-4$ : Chemokine (C-X-C motif) ligand 4; GSK3 $\beta$ : Glycogen synthase kinase-3 $\beta$; HGF: Hepatocyte growth factor; mTOR: Mammalian target of rapamycin; Mcl1: Myeloid leukemia cell differentiation; Bax: BACL2-Associated X protein; Wnt: Wingless-related integration site; JNK: C-Jun N-terminal kinases; mTOR: Mammalian target of rapamycin;VEGF: Vascular endothelial growth factor; BCL-2: B-cell lymphoma 2; BCl-xL: B-cell lymphoma-extra large; hTERT: Human telomerase reverse transcriptase; VEGF: Vascular endothelial growth factor; VEGFR: VEGF receptors; HUVECs: Human umbilical vein endothelial cells; FADD: Fas-associated death
\end{abstract} domain.

\section{Acknowledgements}

Authors are thankful to Dr. A. S. Moses, Principal, Ewing Christian College, and Dr. Shonali Chaturvedi, Head, Department of Botany, Ewing Christian College, for providing necessary facilities needed to complete this review article. Thanks are due to Prof. G. Kumar, Head, Department of Botany, University of Allahabad, for being the constant source of inspiration.

\section{Authors' contributions}

SS conceptualized the objective of the article, collected the data, and prepared the original draft of the manuscript. PM collected some data and edited the manuscript. SKM analyzed and interpreted the collected data and reviewed the draft of the manuscript. The manuscript was finally read and approved by all the authors. All authors read and approved the final manuscript.

\section{Funding}

We declare that there is no funding source for the above article.

\section{Availability of data and materials \\ Not applicable.}

\section{Declarations}

Ethics approval and consent to participate

Not applicable.

\section{Consent for publication}

Not applicable.

\section{Competing interests}

We the authors (Saima Sohrab, Pratibha Mishra, Dr. Sanjay Kumar Mishra) declare that we do not have any conflict of interest with any one with respect to our manuscript entitled "Evaluation of phytochemical profile and pharmacological properties of Costus speciosus (Koen.) Sm.: A synoptical review."

Received: 3 October 2021 Accepted: 12 November 2021

Published online: 04 December 2021

\section{References}

Abirami K, Baskaran V, Singh DR, Gopinath P, Sakthivel K, Roy SD (2014) Phytochemical profile and antifungal activity of Costus sp of Bay Islands. $J$ Andaman Sci Assoc 19(1):45-49

AlSaadi BH, AlHarbi SH, Ibrahim SRM, El-Kholy AA, ElAgamy DS, Mohamed GA (2018) Hepatoprotective activity of Costus speciosus (Koen. ex. Retz.) against paracetamol-induced liver injury in mice. Afr J Tradit Complement Altern Med 15(2):35-41. https://doi.org/10.21010/ajtcam.v15i2.5

Al-Attas AA, El-Shaer NS, Mohamed GA, Ibrahim SR, Esmat A (2015) Antiinflammatory sesquiterpenes from Costus speciosus rhizomes. J Ethnopharmacol 176:365-374. https://doi.org/10.1016/j.jep.2015.11.026

Anonymous (2007) The wealth of India: first supplement series (raw materials). National Institute of Science Communication and Information Resources, CSIR 2:211-213

Ariharan VN, Meena Devi VN, Rajakokhila M, Nagendra Prasad P (2012) Antibacterial activity of Costus speciosus rhizome extract on some pathogenic bacteria. Int J Adv Lif Sci. https://doi.org/10.13140/2.1.3715.5844

Arunprasath A, Gomathinayagam M (2014) Qualitative study of Costus speciosus (Koen ex. Retz.) Sm. and its potentiality against human pathogenic microbes. Int J Pharmaceut Biol Arch 5:93-98

Asrani SK, Devarbhavi H, Eaton J, Kamath PS (2019) Burden of liver diseases in the world. J Hepatol 70(1):151-171. https://doi.org/10.1016/j.jhep.2018. 09.014

Bandara BMR, Fernando IHS, Hewage CM, Karunaratne V, Adikaram NKB, Wijesundara DSA (1989) J Natl Sci Counc Sri Lanka 17(1):1-13. https:// doi.org/10.4038/jnsfsr.v17i1.8236

Banerji R, Prakash D, Patnaik GK, Nigam SK (1982) Indian Drugs 20(2):51-54

Baskar AA, Al Numair KS, Alsaif MA, Ignacimuthu S (2012) In vitro antioxidant and antiproliferative potential of medicinal plants used in traditional Indian medicine to treat cancer. Redox Rep 17(4):145-156. https://doi. org/10.1179/1351000212Y.00000000017

Beckman JS, Chen J, Ischiropoulos H, Crow JP (1994) Oxidative chemistry of peroxynitrite. Methods Enzymol 233:229-240. https://doi.org/10.1016/ s0076-6879(94)33026-3

Benny M (2004) Insulin plant in gardens. Nat Prod Radian 3(5):349-350

Bhattacharya S, Parikh A, Debnath P, Pandey V, Neogy N (1972) Anticholinesterase activity of Costus speciosus alkaloids. Indian J Pharm 4(3):178-179

Bhuyan B, Zaman K (2008) Evaluation of hepatoprotective activity of rhizomes of Costus speciosus (J. Kanji) Smith. Pharmacog Online 3:119-126

Borkar VS, Gangurde HH, Gulecha VS, Bhoyar PK, Mundada AS (2010) Evaluation of in vitro antihelmintic activity of leaves of Butea monosperma. Int J Phytomed 2:31-35. https://doi.org/10.5138/ijpm.2010.0975.0185. 02005

Borkataky M, Kakoti BB, Saikia LR (2014) Analysis of Primary and Secondary Metabolite Profile of Costus speciosus (Koen Ex.Retz.) Sm. Rhizome. J. Nat. Prod. Plant Resour 4(3):71-76.

Botanical survey of India (2019) https://bsi.gov.in/

Chakraborty GS (2009) Indian J Pharm Educ Res 43(1):96-98

Chakre OJ (2010) The wealth of India-a CSIR's encyclopaedia of information resource on economic plants, animals and minerals. Cur Sci 99(7):969-971

Choudhury N, Chandra KJ, Ansarul H (2012) Effect of Costus speciosus Koen on reproductive organs of female albino mice. Int Res J Pharm 3(4):200-202

Consumer Medicine Information-News Medical Life Sciences (2019)

Contreras-Zentella ML, Hernández-Muñoz R (2016) Is liver enzyme release really associated with cell necrosis induced by oxidant stress? Oxid Med Cell Longev. https://doi.org/10.1155/2016/3529149

Dabur India Ltd. Ketaki: Costus speciosus medicinal uses, Dabur. https://www. dabur.com/amp/in/en-us/about/science-of-ayurveda/herbal-medic inal-plants/ketaki-plant.

Daisy P, Eliza J, Ignacimuthu S (2008) Influence of Costus speciosus (Koen.) Sm. Rhizome extracts on biochemical parameters in streptozotocin induced diabetic rats. Health Sci 54(6):675-681. https://doi.org/10.1248/jhs.54. 675

Devi DV, Urooj A (2010) Nutritive profile and a ntioxidant components of Costus speciosus (Koen.) Sm. and Costus igneus Nak. Indian J Natl Prod Resour 1(1):116-118

Dubey S, Verma VK, Sahu AK, Jain AK, Tiwari A (2010) Evaluation of Diuretic activity of Aqueous and Alcoholic Rhizomes extracts of Costus speciosus Linn in Wister Albino mice. IJRAP 1 (2):648-652 
Duraipandiyan V, Al-Harbi NA, Ignacimuthu S, Muthukumar C (2012) Antimicrobial activity of sesquiterpene lactones isolated from traditional medicinal plant, Costus speciosus (Koenex. Retz.) Sm. BMC Complement Altern Med 12:2-6. https://doi.org/10.1186/1472-6882-12-13

El-Far AH, Abou-Ghanema II (2013) Biochemical and hematological evaluation of Costus speciosus as a dietary supplement to Egyptian buffaloes. Afr J Pharm Pharmacol 7(42):2774-2779. https://doi.org/10.5897/AJPP2013. 3519

El-Far AH, Shaheen HM, Alsenosy AW, El-Sayed YS, Jaouni SK, Mousa SA (2018) Costus speciosus: traditional uses, phytochemistry, and therapeutic potentials. Phcog Rev 12:120-127. https://doi.org/10.2174/1570163813 666160802154403

Eliza J, Daisy P, Ignacimuthu S, Duraipandiyan V (2009) Normo-glycemic and hypolipidemic effect of costunolide isolated from Costus speciosus (Koen. ex. Retz.) Sm. in streptozotocin-induced diabetic rats. Chem Biol Interact. 179(2-3):329-34. https://doi.org/10.1016/j.cbi.2008.10.017

Eliza J, Daisy P, Ignacimuthu S (2010) Antioxidant activity of costunolide and eremanthin isolated from Costus speciosus (Koen. ex. Retz.) sm. Chem Biol Interact. 188(3):467-472. https://doi.org/10.1016/j.cbi.2010.08.002

Englberger K (2009) Invasive weeds of Pohnpei: a quide for identification and public awareness. Centre for Agriculture and Bioscience International (CABI) 29

Foyer $\mathrm{CH}$, Noctor G (2005) Oxidant and antioxidant signaling in plants: a reevaluation of the concept of oxidative stress in a physiological context. Plant, Cell Environ 28:1056-1071. https://doi.org/10.1111/j.1365-3040. 2005.01327.x

Girgis SM, Shoman TMT, Kassem SM, El-Din AE, Abdel-Aziz KB (2015) Potential protective effect of Costus speciosus or its nanoparticles on streptozotocin-induced genotoxicity and histopathological alterations in rats. J Nutr Food Sci S3(2):2-7

Gottfredsen RH, Larsen UG, Enghild JJ, Petersen SV (2013) Hydrogen peroxide induce modifications of human extracellular superoxide dismutase that results in enzyme inhibition. Redox Biol 1(1):24-31. https://doi.org/10. 1016/j.redox.2012.12.004

Govindarajan R, Vijayakumar M, Pushpangadan P (2005) Antioxidant approach to disease management and the role of 'rasayana' herbs of ayurveda. J Ethnopharmacol 99(2):165-178. https://doi.org/10.1016/j.jep.2005.02. 035

Gupta D (2015) Methods for determination of antioxidant capacity: a review. Int J Pharm Sci Res. https://doi.org/10.13040/IJPSR.0975-8232.6(2). 546-66

Gupta RK (2010) Medicinal and aromatic plants. CBS Publ Distrib 234:499

Gyawali R, Ibrahim SA (2014) Natural products as antimicrobial agents. Food Control 46:412-429. https://doi.org/10.1016/j.foodcont.2014.05.047

Habsah M, Amran M, Mackeen MM, Lajis NH, Kikuzaki H, Nakatani H, Rahman A, Ghafar A, Ali AM (2000) Screening of Zingiberaceae extracts for antimicrobial and antioxidant activities. J Ethnopharmacol 72(3):403-410. https://doi.org/10.1016/s0378-8741(00)00223-3

Halliwell B (1991) Drug antioxidant effects. Drugs 42(4):569-605. https://doi. org/10.2165/00003495-199142040-00003

Hazai E, Monostory K, Bakos A, Zacher G, Vereczkey L (2001) About hepatotoxicity of paracetamol overdose. Orv Hetil 142(7):345-349

Heard KJ (2008) Acetylcysteine for acetaminophen poisoning. N Engl J Med 359(3):285-292. https://doi.org/10.1056/NEJMct0708278

IARC (1986) Monograph on the evaluation of carcinogenic risks to humans. International Agency for Research on Cancer, Paris, p 40

India Brand Equity Foundation (2020) https://www.ibef.org/

Jha MK, Alam MB, Hossain MS, Islam A (2010) In vitro antioxidant and cytotoxic potential of Costus speciosus (Koen) Smith rhizome. Int J Pharm Sci Res 1(10):138-44. https://doi.org/10.13040/IJPSR.0975-8232.1(10).138-44

Jiang K, Delin W, Larsen K (2000) Zingiberaceae. Flora China 24:322-377

Kala C, Ali SS, Chaudhary S (2016) Comparative pharmacognostical evaluation of Costus speciosus (wild ginger) and Zingiber officinale (ginger) rhizome. Int J Curr Pharm Res 8(4):19-23. https://doi.org/10.22159/ijcpr.2016v $8 i 4.15270$

Kang KS (2013) Abnormality on liver function test. Pediatr Gastroenterol Hepatol Nutr 16(4):225-232. https://doi.org/10.5223/pghn.2013.16.4.225

Karimi E, Jaafar HZE, Ahmad S (2013) Antifungal, anti-inflammatory and cytotoxicity activities of three varieties of Labisia pumila benth: from microwave obtained extracts. BMC Complement Altern Med 13:1-10. https://doi.org/10.1186/1472-6882-13-20
Kasote DM, Katyare SS, Hegde VM, Bae H (2015) Significance of antioxidant potential of plants and its relevance to therapeutic applications. Int J Biol Sci 11(8):982-991. https://doi.org/10.7150/ijbs.12096

Kaushik ML, Jalalpure SS (2011) Evaluation of anti-inflammatory effect of ethanolic and aqueous extracts of Curcuma zedoaria rosc root. Int J Drug Develop Res 3(1):360-365

Khamar BM (2002) The process of preparing the tropical anti-inflammatory/ analgesic preparation. WO-02/085394

Kim DY, Choi BY (2019) Costunolide - a bioactive sesquiterpene lactone with diverse therapeutic potential. Int J Mol Sci 20:2926. https://doi.org/10. 3390/ijms20122926

Kirchoff BK, Rutishauser R (1990) The phyllotaxy of Costus (Costaceae). Bot Gaz 151(1):88-105. https://doi.org/10.1086/337808

Kulkarni D (2013) Acute paracetamol toxicity: a case report. Indian J Appl Res 3(12):466-468

Kumar A, Chand G, Agnihotri VK (2018a) A new oxo-sterol derivative from the rhizomes of Costus speciosus. Nat Prod Res 32(1):18-22. https://doi.org/ 10.1080/14786419.2017.1324962

Kumar A, Maurya AK, Chand G, Agnihotri VK (2018b) Comparative metabolic profiling of Costus speciosus leaves and rhizomes using NMR GC-MS and UPLC/ESIMS/MS. Nat Prod Res 32(7):826-833. https://doi.org/10.1080/ 14786419.2017 .1365069

Lee YH, Choo C, Watawana MI, Jayawardena N, Waisundara VY (2015) An appraisal of eighteen commonly consumed edible plants as functional food based on their antioxidant and starch hydrolase inhibitory activities. J. Sci. Food Agric. 95(14):2956-2964. https://doi.org/10.1002/jsfa. 7039

Lewis ME (2001) Should we be concerned about herbal remedies. J Ethnopharmacol 75(2-3):141-164. https://doi.org/10.1016/s0378-8741(00) 00394-9

Lijuan W, Kupittayanant P, Chudapongse N, Wray S, Kupittayanant S (2011) The effects of wild ginger (Costus speciosus (Koen) Smith) rhizome extract and diosgenin on rat uterine contractions. Reprod Sci 18(6):516-524. https://doi.org/10.1177/1933719110391278

Maheswari C, Maryammal R, Venkatanarayanan R (2008) Hepatoprotective activity of Orthosiphon stamineus on liver damage caused by paracetamol in rats. Jordan J Biol Sci 1(3):105-108

Maji P. Dhar DG, Misra P, Dhar P (2020) Costus speciosus (Koen. ex. Retz.) Sm. current status and future industrial prospects. Ind Crops Prod 152:11257

Malabadi RB (2005) Antibacterial activity in the rhizome extracts of Costus speciosus (Koen.). J Phytol Res. 18(1):83-85

Mau UL, Eric Lai YC, Wang NP, Chen CC, Chang CH, Chyau CC (2003) Composition and antioxidant activity of the essential oil from Curcuma zedoaria. Food Chem 82(4):583-659. https://doi.org/10.1016/S0308-8146(03) 00014-1

Mazumdar T, Hussain MS (2021) A comprehensive review of pharmacological and toxicological properties of Cheilocostus speciosus (J. Koenig) C.D. Specht. Trends Phytochem Res 5(1):2021-12

Mishra G, Sinha R, Verma N, Khosa RL, Garg VK, Singh P (2009) Hepatoprotective activity of alcoholic and aqueous extracts of Wedelia Chinensis. Pharmacologyonline 1:343-356

Mosihuzzaman M, Nahar N, Ali L, Rokeya B, Khan AK, Nur-E-Alam M, Nandi RP (1994) Hypoglycemic effects of three plants from eastern Himalayan belt. Diabetes Res 26(3):127-138

Muthukumaran P, Thiyagarajan G, Arun Babu R, Lakshmi BS (2018) Raffinose from Costus speciosus attenuates lipid synthesis through modulation of PPARs/SREBP1c and improves insulin sensitivity through PI3K/AKT. Chem Biol Interact 284:80-89. https://doi.org/10.1016/j.cbi.2018.02.011

Nadkarni KM (2009) Indian materia medica. Bombay Popular Prakashan 1:385-386

Nair SV, Hettihewa M, Rupasinghe HP (2014) Apoptotic and inhibitory effects on cell proliferation of hepatocellular carcinoma HepG2 cells by methanol leaf extract of Costus speciosus. Biomed Res Int. https://doi.org/10. $1155 / 2014 / 637098$

Nandi A, Yan LJ, Jana CK, Das N (2019) Role of catalase in oxidative stressand age-associated degenerative diseases. Oxid Med Cell Longev 9613090:19. https://doi.org/10.1155/2019/9613090

National diabetes and diabetic retinopathy survey India 2015-2019 - A summary report. https://npcbvi.gov.in/writeReadData/mainlinkFile/File3 42.pdf 
National medicinal plants board (2021) https://www.nmpb.nic.in/medicinal_ list

Nehete J, Bhatia M, Narkhede M (2010) In-vitro evaluation of antioxidant activity and phenolic content of Costus speciosus (Koen) J. E. Sm. Iran J Pharm Res 9(3):271-277

Nordgren M, Fransen M (2014) Peroxisomal metabolism and oxidative stress. Biochimie 98:56-62. https://doi.org/10.1016/j.biochi.2013.07.026

Ozioma E, Okaka A (2019) Herbal medicines in African traditional medicine. In: Ozioma EJ, Chinwe OAN (eds) Herbal medicine. Intratech Open, New York, pp 1-25

Pai Kotebagilu N, Reddy Palvai V, Urooj A (2014) Protective effect of selected medicinal plants against hydrogen peroxide induced oxidative damage on biological substrates. Int J Medicinal Chem. https://doi.org/10.1155/ 2014/861084

Pawar VA, Pawar PR (2014) Costus speciosus: an important medicinal plant. Int J Sci Res 3(7):28-32

Perera HK, Premadasa WK, Poongunran J (2016) A-glucosidase and glycation inhibitory effects of Costus speciosus leaves. BMC Complement Altern Med 16:2. https://doi.org/10.1186/s12906-015-0982-z

Philip Robinson J, John Britto S, Balakrishnsn V (2009) Micropropagation of Costus speciosus (Koem.ex.retz) Sm., an antidiabetic plant by using explants of Pseudostems. Bot Res Int 2(3):182-185

Pietta PG (2000) Flavonoids as antioxidants. J Nat Prod 63(7):1035-1042. https://doi.org/10.1021/np9904509

Pitchai D, Roy A, Banu S (2014) In vitro and in silico evaluation of NF-KB targeted costunolide action on estrogen receptor-negative breast cancer cells-A comparison with normal breast cells. Phytother Res 28(10):1499-1505. https://doi.org/10.1002/ptr.5155

Prabhu NM, Pai PG, Kumar SV, Gaurav AD, Silva CSM, Ullal SD, Shenoy KA, Sushma DS (2014) Diuretic activity of aqueous ethanolic extract of leaves of Costus speciosus in normal Wistar albino rats. Res J Pharmaceut Biol Chem Sci 5(3):127-132

Rani AS, Sulakshana G, Patnaik S (2012) Costus speciosus, an antidiabetic plant Review. FS J Pharm Res 1:3

Rastogi RP, Mehrotra BN (2004) Compendium of Indian medicinal plants. National Institute of Science Communication and Information Resources, New Delhi, p 215

Rastogi RP, Mehrotra BN (2004b) Compendium of Indian Medicinal plants, Central Drug Research Institute, Lucknow and National Institute of Science Communication and Information. Resources 4:224-225

Raveendran R (2015) Qualitative and quantitative analysis of phytochemicals of Costus speciosus. Int J Health Sci Res 5(12):170-175. https://doi.org/ 10.13140/RG.2.2.34278.24646

Rayan NA, Baby N, Pitchai D, Indraswari F, Ling EA, Lu J, Dheen T (2011) Costunolide inhibits proinflammatory cytokines and iNOS in activated murine BV2 microglia. Front Biosci (elite Ed) 3:1079-1091. https://doi. org/10.2741/e312

Roy A, Manikkam R (2015) Cytotoxic impact of costunolide isolated from Costus speciosus on breast cancer via differential regulation of cell cyclean in-vitro and in-silico approach. Phytotherapy Res 29(10):1532-1539. https://doi.org/10.1002/ptr.5408

Selim S, Al Jaouni S (2016) Anti-inflammatory, antioxidant and antiangiogenic activities of diosgenin isolated from traditional medicinal plant, Costus speciosus (Koen ex.Retz.) sm. Nat Prod Res. 30(16):1830-03. https://doi. org/10.1080/14786419.2015.1065493

Sharifi-Rad J, Salehi B, Stojanovi'c-Radi'c ZZ, Fokou PVT, Sharifi-Rad M, Mahady GB, Sharifi-Rad M, Masjedi,MR, Lawal TO, Ayatollahi SA (2017) Medicinal plants used in the treatment of tuberculosis. Ethnobotanical and ethnopharmacological approaches. Biotechnol Adv

Sharma R, Yang Y, Sharma A, Awasthi S, Awasthi YC (2004) Antioxidant role of glutathione S-transferases: protection against oxidant toxicity and regulation of stress-mediated apoptosis. Antioxid Redox Signal 6(2):289-300. https://doi.org/10.1089/152308604322899350

Shrivastava S, Singh P, Mishra G, Jha KK, Khosa RL (2011) Costus speciosus (Keukand): a review. Der Pharmacia Sinica 2(1):118-128

Singh N (2011) Wild edible plants: a potential source of neutraceuticals. Int J Pharma Sci Res 2(12):216-225

Singh P, Khosa RL, Srivastava S, Mishra G, Jha KK, Srivastava S, Sangeeta Verma RK, Tahseen MA (2014) Pharmacological study and establishment of quality parameters of aerial parts of Costus speciosus - a well known tropical folklore medicine. Asian Pac J Trop Biomed 4(6):486-491. https://doi.org/10.12980/APJTB.4.2014C1103

Specht CD, Stevenson WD (2006) A new phylogeny-based generic classification of Costaceae (Zingiberales). Taxon 55(1):153-163. https://doi.org/ $10.2307 / 25065537$

Srivastava S, Singh P, Jha KK, Mishra G, Srivastava S, Khosa RL (2012) Evaluation of anti-arthritic potential of the methanolic extract of the aerial parts of Costus speciosus. J Ayurveda Integr Med 3(4):204-208. https://doi.org/ 10.4103/0975-9476.104443

Srivastava S, Singh P, Jha KK, Mishra G, Srivastava S, Khosa RL (2013) Antiinflammatory, analgesic and antipyretic activities of aerial parts of Costus speciosus Koen. Indian J Pharm Sci 75(1):83-88. https://doi.org/10.4103/ 0250-474X.113532

Srivastava S, Singh P, Mishra G, Jha KK, Khosa RL (2011) Costus speciosus (Keukand): a review. Der Pharmacia Sinica 2(1):118-128

Sulakshana G, Rani AS (2015) In vitro evaluation of antifungal activity in three different species of Costus. World J Pharm Res 4(9):1139-1144

Sunitha D (2016) A review on antioxidant methods. Asian J Pharm Clin Res 9(2):4-32. https://doi.org/10.22159/ajpcr.2016.v9s2.13092

Swati S, Agarwal P (2015) Kebuka (Costus speciosus): a critical review. World J Pharm Pharm Sci 4:421-431

Thambi M, Shafi MP (2015) Rhizome essential oil composition of Costus speciosus and its antimicrobial properties. Int J Pharm Res Allied Sci 4(1):28-32

Vaidya M, Shingadia H (2020) Antimicrobial activity of Costus speciosus (J. Koieng) Sm. World J Pharm Res 9(2):959-963. https://doi.org/10.20959/ wjpr20202-16672

Verma N, Khosa RL (2009) Evaluation of protective effects of ethanolic extract of Costus speciosus (Koenig). Sm Rhizomes on carbon tetrachloride induced hepatotoxicity in rats. Natl Prod Radiance. 8(2):123-126

WHO (2012) Guidelines on good agricultural and collection practices (GACP) for medicinal plants

World Health Organization (2002-2005) Traditional medicine strategy (WHO/ EDM/TRM/2002.1)

Yin SY, Wei WC, Yang Jian FY, NS, (2013) Therapeutic applications of herbal medicines for cancer patients. Evid Based Complement Alternat Med. https://doi.org/10.1155/2013/302426

Younus H (2018) Therapeutic potentials of superoxide dismutase. Int J Health Sci 12(3):88

\section{Publisher's Note}

Springer Nature remains neutral with regard to jurisdictional claims in published maps and institutional affiliations.

\section{Submit your manuscript to a SpringerOpen ${ }^{\circ}$ journal and benefit from:}

- Convenient online submission

- Rigorous peer review

- Open access: articles freely available online

- High visibility within the field

- Retaining the copyright to your article

Submit your next manuscript at springeropen.com 